\title{
Evaluation of the cytotoxic activity of Tamarix articulata and its anticancer potential in prostate cancer cells
}

\author{
Abdullah M. Alnuqaydan ${ }^{1 *}$, Abdulmajeed G. Almutary', Ohoud Y. Alshehri², Hanan Ali Henidi ${ }^{3}$, Abdullah M. Alajlan ${ }^{4}$, \\ Abdullah Al Tamim ${ }^{4}$, Abdullah Alowaifeer ${ }^{4}$, Mohd Younis Rather ${ }^{5}$, Bilal Rah ${ }^{1 *}$ (D) \\ ${ }^{1}$ Department of Medical Biotechnology, College of Applied Medical Sciences, Qassim University, Buraidah, Saudi Arabia. \\ ${ }^{2}$ Department of Biochemistry, College of Medicine, Al-Imam Mohammad Ibn Saud Islamic University (IMSIU), Riyadh, Saudi Arabia. \\ ${ }^{3}$ Research Department, Health Sciences Research Center, Princess Nourah Bint Abdul Rahman University, Riyadh, Saudi Arabia. \\ ${ }^{4}$ Reference Laboratory for Food Chemistry, Saudi Food Drug Authority SFDA, Riyadh, Saudi Arabia. \\ ${ }^{5}$ Postgraduate Department of Pharmacology, Government Medical College, Srinagar, India.
}

\section{ARTICLE INFO \\ Received on: 24/07/2021 \\ Accepted on: 25/10/2021 \\ Available Online: 05/02/2022}

\section{Key words:}

Tamarix articulata, plant

extracts, metastasis, anticancer, prostate cancer, apoptosis, cell motility, cell invasion.

\begin{abstract}
Anticancer drugs induce cell death mechanism in tumor cells by various modes, which include apoptosis, autophagy, and necroptosis. However, they become ineffective when tumor cells enter metastasis. Thus, searching for plantbased extracts/compounds to curtail metastasis is extremely important. This study aims to evaluate the anticancer potential of Tamarix articulata (TA) extract against prostate cancer cells. MTT, Brd U, and trypan blue assays were carried out to evaluate the cell viability. Terminal Transferase dUTP Nick End Labeling assay was carried out to determine apoptotic cells. Clonogenic, wound-healing, and Boyden chamber assay was conducted to evaluate the anticlonogenic, antimotility, and anti-invasive potential of TA. Zymography and immunoblotting were carried out to check the activity and expression of metalloproteases and proteins associated with metastasis. Our results demonstrated that TA extract significantly inhibits cell viability and clonogenic property and displays $\mathrm{IC}_{50}$ values in the $245-289 \mu \mathrm{g} / \mathrm{ml}$ range. TA extract significantly abrogates the motility and invasive property of LnCaP cells in a dose-dependent manner. Mechanistically, TA extracts downregulate the expression of phosphoinositide 3-kinaseprotein kinase B-protein kinase B (PI3K-Akt), transforming growth factor-beta-Sma genes and the Drosophila Mad, mothers against decapentaplegic protein $2 / 3$ (TGF- $\beta$-SMAD2/3), and matrix metalloproteinases-2/9 (MMP-2/9) with concomitant upregulation of tissue inhibitor of metalloproteinase 1 (TIMP1) expression in LnCaP cells. Additionally, we observed a dose-dependent downregulation of snail and vimentin with the upregulation of E-cadherin protein expression in LnCaP cells. TA extract exhibits an antiproliferative effect and abrogates cell motility and invasion by downregulating PI3K-Akt, TGF- $\beta$-SMAD2/3, MMP-2/9, snail, and vimentin with concomitant upregulation of E-cadherin and TIMP1 expression in prostate cancer cells.
\end{abstract}

\section{INTRODUCTION}

Tumor metastasis is a series of events governed by complex mechanisms that are initiated by the detachment of tumor cells, followed by invasion, migration, endothelial cell adhesion, and finally reestablishment of tumor growth at distant

\footnotetext{
*Corresponding Author

Abdullah M. Alnuqaydan, Department of Medical Biotechnology, College of Applied Medical Sciences, Qassim University, Buraidah, Saudi Arabia. E-mail: ami.alnuqaydan@qu.edu.sa Bilal Rah, Department of Medical Biotechnology, College of Applied Medical Sciences, Qassim University, Buraidah, Saudi Arabia. E-mail: b.rah@qu.edu.sa
}

sites (Roodman, 2004). Most tumor cells undergo apoptosis by chemotherapeutic drugs (Strasser and Vaux, 2020). Some cells sustain chemotherapeutic drugs and often evade cell death mechanisms due to the accumulation of oncogenic mutations, which enhance tumor cell growth (Strasser and Vaux, 2020). These resistant cells can successfully advance metastatic dissemination to distant sites and pose a serious challenge to the current chemotherapeutics regimen (Valastyan and Weinberg, 2011). Despite significant advances being made in the conventional therapeutics of cancer, tumor metastasis is still a major problem (Baudino, 2015; Valastyan and Weinberg, 2011). Owing to the absence of any therapeutics against metastasis, most cancer-related deaths occur due to metastasis (Mehlen and Puisieux, 2006). It is one of the leading metastasis-associated deaths in Western countries; approximately $50 \%$ of prostate cancer patients 
clinically present with bone metastasis (Stavridi et al., 2010). The therapeutic interventions for prostate cancer are surgery (radical prostatectomy), radiotherapy, and adjuvant chemotherapy (Suardi et al., 2014). The bone-associated metastasis in prostate cancer is extremely resistant to radiotherapy and to the present regiment of ablation of androgen therapy (Suardi et al., 2014). Owing to the development of androgen-independent prostate cancer, relapse is inevitable approximately after 18 months in prostate cancer metastasis. This indicates that there is no therapeutic option for metastatic prostate cancer patients thereafter (Zhang et al., 2017). For this reason, new therapeutics are urgently required to treat metastatic prostate cancer.

Various cancers, including prostate cancer, are less evident in the Arab population compared to Western societies (Hilal et al., 2015). This may be due to the difference in prostate cancer screening, poor counseling for prostate-specific antigen (Arafa and Rabah, 2017), low androgenic factors with high polyunsaturated fats in Mediterranean foods, which maintains the testosterone level under a certain level (Al-Abdin and Al-Beeshi, 2018), and dietary advantages of plants having a great medicinal value (Ito, 2014).

Ever since ancient times, plants have been used to treat numerous ailments (Kaur et al., 2011). Owing to the presence of secondary metabolites such as alkaloids, phenolics, and terpenoids, which act as defense mechanisms against both abiotic and biotic stresses, these compounds have promising medicinal importance (Verma and Shukla, 2015). One such plant in the deserts of Saudi Arabia containing a wide variety of secondary metabolites is Tamarix articulata (TA) (Alnuqaydan and Rah, 2019). This plant belongs to the family Tamaricaceae and is a halophytic plant growing in extremely harsh and arid conditions in the deserts of Saudi Arabia (Said et al., 2018). Commonly called Athal in the Arabic language, TA has been extensively used as folk medicine by the Tafilalet, a tribal people in the southeastern area of Morocco. TA is a halophytic plant growing in extremely harsh environmental conditions. It exhibits promising biological activities such as antioxidant, antidiabetic, hypolipidemic, antibacterial, and hepatoprotective activities (Alnuqaydan and Rah, 2019, 2020; Bencherif et al., 2015; Hebi et al., 2017, 2018; Said et al., 2018). The plant is woody and possesses great medicinal value. Traditionally, the plant is used to treat various ailments such as gastrointestinal diseases, skin diseases, heart diseases, and other ailments (Said et al., 2018). The phytochemical analysis of the methanolic extract of TA by liquid chromatography with tandem mass spectrometry (LC-MS) analysis reveals the identification of more than 200 compounds. The key phytochemicals identified from the methanolic extract of TA by LC-MS were reported to exhibit anticancer activities against various cellular models. Crude extracts of the plant have been reported to exhibit anticancer properties by inhibiting cell viability in various types of cancer cells in other parts of the world (Shaalan et al., 2018). Consistent with the preliminary reports, our group also revealed that the methanolic extract of TA demonstrates promising antiproliferative activity against breast, colorectal, and hepatocellular carcinoma cells (Alnuqaydan and Rah, 2020). However, no data are yet available for the antimetastatic activity of TA extract. For this reason, the current study aims to evaluate the antiproliferative and antimetastatic activities of TA extract against prostate cancer cells and to investigate the possible underlying inhibitory mechanism against prostate cancer cells.

\section{MATERIALS AND METHODS}

\section{Collection of plant material and preparation of extract}

The TA plant material is scientifically well-characterized and belongs to clade: angiosperms, order: Caryophyllales, family: Tamaricaceae, genus: Tamarix, and species: Tamarix articulata, which was collected in August 2019 from the deserts of Qassim province in the Kingdom of Saudi Arabia. A methanolic extract derived from the dry leaves was prepared as per the standard protocol published in our previous work (Alnuqaydan and Rah, 2020). After collection, the TA parts were first air-dried in the shade to remove the moisture completely. Using sharp blades, TA was chopped into small pieces, followed by grinding in a kitchen blender to produce a fine powder. After weighing, $12 \mathrm{~g}$ of TA powder was added to $300 \mathrm{ml}$ of $100 \%$ methanol and constantly stirred with a magnetic bead for 5 days at room temperature. The mixture obtained was first filtered through cheesecloth to remove the bulk, followed by filtration through a Whatman filter paper in an autoclaved glass beaker. The methanol (solvent) was completely evaporated from the plant extract mixture in a glass beaker by keeping the temperature of the hot plate at $45^{\circ} \mathrm{C}$ to avoid the degradation of heat-labile compounds. After the complete evaporation of the solvent, the fine powder of residue left in the glass beaker was collected and stored at $4^{\circ} \mathrm{C}$ in stored vials for future experiments to evaluate the biological activities of the TA.

\section{Sample preparation}

Plant metabolites from TA were extracted as described by previously published work (Alnuqaydan and Rah, 2020). Briefly, $50 \mathrm{mg}$ of plant material was weighed into an Eppendorf tube, and $1 \mathrm{ml}$ of methanol was added, vortexed for 30 seconds, and then centrifuged for 15 minutes at 5,000 rpm. After centrifugation, $200 \mu \mathrm{l}$ of the supernatant was diluted fivefold with HPLC grade acetonitrile and then filtered through a $0.2 \mu \mathrm{m}$ filter. Afterward, the metabolic filtrate was transferred into an LC vial for analysis.

\section{LC-MS metabolomic analysis and data processing}

The analysis was carried out on an LC-MS consisting of an ACQUITY UPLC I-Class System (Waters Technologies, USA) coupled to a 6,500 Qtrap (AB Sciex, Canada). The chromatographic separation was carried out on a Zorbax XDB C18 column $(2.1 \times 150 \mathrm{~mm} .3 .5 \mu \mathrm{m})$ (Agilent, USA) and kept at $40^{\circ} \mathrm{C}$ with a flow rate of $300 \mu \mathrm{l} /$ minute. The mobile phase consisted of A $(0.1 \%$ formic acid in HPLC grade water) and B ( $0.1 \%$ formic acid in HPLC grade acetonitrile). The linear gradient elution was as follows: 2\% B (from 0 to 2), 95\% B (from 2 to 24), $95 \% \mathrm{~B}$ (held for 2 minutes), and then 4 minutes equilibration time. Electrospray ionization mass spectra (MS) were acquired in the positive $(\mathrm{ES}+)$, with an electrode voltage of $5500 \mathrm{~V}$. The declustering potential was set at $90 \mathrm{~V}$, and the entrance potential was $10 \mathrm{~V}$. Nitrogen was used as curtain gas (30 psi) and nebulizer gas on the MS. Spectra were collected with a mass range of $100-900 \mathrm{~m} / \mathrm{z}$. Data files from the LC were converted to MZxml format using MS Convert (ProteoWizard 3.0.20270). Analysis of the data was conducted using MZmine software (version 2.53). After importing the data into MZmine, a minimum intensity cutoff of 1,000 was applied, and the retention time was adjusted with a tolerance of 0.2 minutes. An adjusted peak was then aligned 
into one mass list to facilitate identification and comparison. The Kyoto encyclopedia of genes and genomes database software was used to identify compounds of interest in the finalized list based on $\mathrm{m} / \mathrm{z}$ with a tolerance of $30 \mathrm{ppm}$.

\section{Culturing of cells and treatments}

The cellular models of prostate cancer cells (PC-3, LnCaP, DU 145, C4-2b, and VCaP) were ordered and purchased from the American Type Culture Collection (ATCC); however, benign prostate hyperplasia $(\mathrm{BPH})$ cells were procured from Sigma (Merck). All the purchased cell lines were cultured in their respective cell culture media [Roswell Park Memorial Institute-1640 (\#11875101) and Minimal Essential Medium (\#31095029)] in a 5\% CO incubator. The cell culture medium procured from Thermo Fisher Scientific was supplemented with L-glutamine and phenol red. Externally, culture media were added with $1 \%$ penicillin-streptomycin (\#15140122) and 10\% fetal bovine serum (\#16000044) procured from Thermo Fisher Scientific. All the cell lines obtained from ATCC were regularly checked for all Mycoplasma contaminations.

\section{Chemicals, reagents, and antibodies}

Dimethyl sulfoxide (DMSO, \#D2650), phenylmethylsulfonyl fluoride (PMSF, \#52332), propidium iodide (PI, \#4170), 3-(4,5-dimethylthiazol-2-yl)-2,5-diphenyltetrazolium bromide (MTT, \#M5655), triton X-100 (\#T8787), paraformaldehyde (\#158127), 4',6-diamidino-2-phenylindole dihydrochloride (DAPI, \#D8417), and trypan blue (\#T6146) were ordered and purchased from Sigma Aldrich. However, primary antibodies were ordered and bought from cell signaling technology, these being $\beta$-actin (\#4970), phosphoinositide 3-kinase-protein kinase B (PI3K-p110 $\alpha$ ) (\#4249S), protein kinase B (Akt) (\#4691S), p-Akt-Ser473 (\#4060), transforming growth factor-beta (TGF- $\beta$ ) (\#3711S), Sma genes and the Drosophila Mad, mothers against decapentaplegic protein 2 (SMAD2) (\#5339S), SMAD3 (\#9523S), tissue inhibitor of metalloproteinase 1 (TIMP1) (\#8946S), matrix metalloproteinases-2 (MMP-2) (\#40994S), E-cadherin (\#14472S), snail (\#3879S), vimentin (\#5741S), and MMP-9 (\#13667S). From Santa Cruz Biotechnology, secondary antibodies, namely antirabbit IgG (SC-2359) and anti-mouse IgG (SC-2005), coupled with enzyme horseradish peroxidase (HRP) were procured.

\section{Preparation of TA stock solution}

The TA stock solution in DMSO $(100 \mathrm{mg} / \mathrm{ml})$ was prepared, aliquoted, and stored in autoclaved microcentrifuge tubes $(1.5 \mathrm{ml})$ at $-20^{\circ} \mathrm{C}$. At the time of the experiment, stock concentration was diluted with culture media to prepare a working concentration $(10-10,000 \mu \mathrm{g} / \mathrm{ml}$ for exposing prostate cancer cells to varying doses of TA extract.

\section{Cell proliferation assay/cell cytotoxicity assay}

The proliferation of prostate cancer cells was determined by the most used MTT assay (Rah et al., 2012). Briefly, a panel of prostate cancer and transformed cells (PC-3, LnCaP, DU 145, and $\mathrm{BPH}$ ) were subjected to harvesting and seeded at a density of $2 \times 10^{3}$ cells in each well of a 96-well plate. The seeded cells were exposed to various doses of TA extract $(10-10,000 \mu \mathrm{g} / \mathrm{ml})$ along with DMSO control. After incubation lasting for 24 hours in a $5 \% \mathrm{CO}_{2}$ incubator, cells were flooded with $20 \mu \mathrm{l}$ of $2.5 \mathrm{mg} / \mathrm{ml}$ MTT dye and incubated for 3 hours, at $5 \% \mathrm{CO}_{2}$ incubator at $37^{\circ} \mathrm{C}$. After incubation, it is necessary to remove the media containing MTT dye and add DMSO to dissolve formazan crystals which are formed by reducing the tetrazolium salts by dehydrogenase and reductase enzymes of live cells. These were formed when cells were incubated in MTT dye. The purple-colored solution obtained after proper mixing or gentle shaking of the 96-well plate was measured at $570 \mathrm{~nm}$ to record absorbance. The $\mathrm{IC}_{50}$ value, which is the concentration of a TA extract to kill half of the cell population, is calculated by using the formula:

$\%$ cell survival $=$ absorbance of compound - absorbance of blank/absorbance of control - absorbance of blank $\times 100$.

\section{Colony formation assay}

LnCaP cells $1 \times 10^{3}$ plated in the 6 -well plates were treated with varying concentrations of TA extract $(67.5,125,250$, and 500 $\mu \mathrm{g} / \mathrm{ml})$ along with control DMSO and staurosporine $(11.663 \mu \mathrm{g} /$ $\mathrm{ml}$ ) (Sinha et al., 2013). The treated cells were incubated in 5\% $\mathrm{CO}_{2}$ at $37^{\circ} \mathrm{C}$ for 5 days. Next, the medium was discarded, and the treated cells were washed with precooled PBS. Following this, the cells were fixed in ice-cooled methanol for 20 minutes and then stained with $0.5 \%$ crystal violet solution for about 15 minutes. The cellular colonies stained in each well of the 6-well plate were photographed with a phase-contrast microscope, and the cells in each colony were counted.

\section{Scratch motility (wound-healing) assay}

Briefly, prostate cancer cells ( $\mathrm{LnCaP}$ ) were harvested from the culture flask, followed by seeding of $5.5 \times 10^{5}$ cells in each well of the 6-well plate (Zilla et al., 2014). After overnight incubation in a $5 \% \mathrm{CO}_{2}$ incubator at $37^{\circ} \mathrm{C}$, a complete matt of the monolayer was formed of the cells. In the middle of each well, a scratch was made with a sterile $200 \mathrm{ul}$ microtip to create a wound. The 6-well plate with serum-free media was employed to wash out detached cells while creating a wound. After clearing detached cells, wound-created wells were exposed to varying concentrations of TA extract, that is, $67.5,125,250$, and $500 \mu \mathrm{g} / \mathrm{ml}$, in the presence of untreated control and positive control camptothecin $2 \mu \mathrm{M}$ for 24 hours. Next, the cells were analyzed under a microscope, and then photographs were taken of areas where the wound was created at 0 hour. The percentage of wound closure was measured by using the formula as follows:

$\%$ age of wound closure $=[1-($ area of wounding after 24 hours/area of the wound at 0 hour $) \times 100 \%]$.

\section{Transwell Boyden chamber invasion assay}

Briefly, $1.25 \times 10^{6} \mathrm{LnCaP}$ cells were harvested, counted, and added uniformly to the culture medium without serum in the upper insert of the Transwell Boyden chamber plate and subsequently subjected to varying doses of TA extract (67.5, 125,250 , and $500 \mu \mathrm{g} / \mathrm{ml}$ ). This occurs in the presence of control (untreated) and camptothecin $2 \mu \mathrm{M}$ as a positive control. The lower chamber was filled with $10 \%$ serum-containing media as the chemoattractant. Resuspended cells exposed to varying concentrations of TA extract tried to move towards the lower chamber containing $10 \%$ serum media. After 24 hours, the porous Matrigel-coated polycarbonate insert membrane was removed, and 
the attached cell inside the insert was completely wiped off with a swab of cotton. These cells that adhered to the bottom outside of the upper insert were fixed in precooled methanol for 15 minutes. This was followed by staining the cells with $0.25 \%$ crystal violet solution in PBS. Then this stained porous biological membrane was put under a microscope to examine cells and subsequently photographed. The cells which can cross the membrane were photographed and counted under a phase-contrast microscope.

\section{Gelatin zymography}

Prostate $(\mathrm{LnCaP})$ cancer $5 \times 10^{5}$ cells were harvested and plated in a 6-well plate as carried out previously (Rah et al., 2012). Cells were exposed to varying concentrations of TA extract $(67.5,125,250$, and $500 \mu \mathrm{g} / \mathrm{ml})$ along with control DMSO and camptothecin $(2 \mu \mathrm{M})$ as a positive control for 24 hours. The conditional media obtained from each treated well along with untreated control and positive control were collected in separate autoclaved $2 \mathrm{ml}$ microcentrifuge tubes. Each sample was subjected to protein estimation by the standard Bradford method. The equal protein concentration of all samples was mixed with loading dye. The samples were loaded in the wells of SDS-PAGE gel containing $0.1 \%$ gelatin, and the gel could resolve by setting the voltage initially at $80 \mathrm{~V}$ and after samples entering the resolving gel set the voltage at $100 \mathrm{~V}$ for 3 hours at $4^{\circ} \mathrm{C}$. The resolved gelatin gel was washed with a $2 \%$ Triton X-100 buffer to remove SDS. The gel with incubation buffer was incubated to renature the MMP for 24 hours at $37^{\circ} \mathrm{C}$. Following this, the gel with Coomassie brilliant blue solution was stained for 1 to 2 hours, followed by distaining of gel with a mild destaining solution to ensure that clear bands appeared. The gelatinase activity was determined by analyzing clear transparent bands against the dark blue background after Coomassie brilliant blue staining.

\section{Immunoblotting}

Briefly, $50 \times 10^{5}$ cells $(\mathrm{LnCaP})$ were plated in each well of the 6-well plate, and they were allowed to adhere overnight to the bottom surface of the well in a $5 \% \mathrm{CO}_{2}$ incubator at $37^{\circ} \mathrm{C}$. The attached LnCaP cells were exposed to varying doses of TA extract $(67.5,125,250$, and $500 \mu \mathrm{g} / \mathrm{ml})$ along with the DMSO vehicle (Rasool et al., 2017). After 24 hours, the treated cells were gently washed with precooled PBS, scraped, and harvested the cells in a sterile microcentrifuge tube. $500 \mu \mathrm{l}$ of lysis buffer, which contained PMSF and protease cocktail inhibitor, was added, and cells repeatedly agitated intermittently for 10 seconds and kept on ice for 2-3 minutes. This was carried out five times to ensure complete lysis. The cell lysate solution was centrifuged at a speed of $12,000 \mathrm{~g}$ for 15 minutes at $4^{\circ} \mathrm{C}$ to collect the supernatant. Using the Bradford method, the collected supernatant was subjected to the process of estimating protein concentration. 15-20 $\mu \mathrm{g}$ protein from each TA exposed cell sample was calculated for loading in SDS-PAGE gel and resolving the gel. This followed the protocol mentioned in the above reference. Then SDS-PAGE gel was transferred onto the PVDF membrane followed by incubation of this membrane in a blocking solution containing $5 \%$ fat-free milk. This served to block nonspecific sites. The PVDF membrane was incubated with primary antibody solution for 3-4 hours at room temperature or overnight at $4^{\circ} \mathrm{C}$. Subsequently, the PVDF membrane was washed with TBST 6 times followed by incubation with secondary antibody labeled with enzyme HRP for 1 hour 30 minutes at room temperature. After incubation was completed, the PVDF membrane was washed with TBST 6 times, and each washing lasted 5 minutes. After washing, cleaning, and drying the PVDF membrane, immunoreactive substances enhanced the process of chemiluminescence to detect the bands on the PVDF membrane. The chemiluminescent signal on the PVDF membrane with the X-ray films was captured after proper exposure under dark conditions or with inbuilt chemiluminescent gel doc.

\section{Cell proliferation (Brd U) assay}

Antiproliferative activity of TA extract against a panel of prostate cancer cell lines was evaluated by using colorimetric method Brd U cell proliferation ELISA kit (Abcam \#Ab126556). Briefly, $2 \times 10^{3}$ cells were plated in each well of the 96-well plate overnight. After adhering properly to the bottom surface of the well, cells were exposed to varying doses $(10-10,000 \mu \mathrm{g} / \mathrm{ml})$ of TA extract for 24 hours at $37^{\circ} \mathrm{C}$ in $5 \% \mathrm{CO}_{2}$ incubator in triplicate. After the exposure of cells to TA extract, as per the manufacturer's instruction, cells were incubated with Brd $\mathrm{U}$ for 2 hours at $37^{\circ} \mathrm{C}$ to incorporate Brd U in DNA. The cells were fixed, permeabilized, and desaturated, followed by gentle washing and aspiration. Cells were incubated with anti-Brd $\mathrm{U}$ monoclonal antibody for 1 hour at room temperature. After proper incubation and removal of unbound fraction of anti-Brd $U$ from wells by gently washing and aspiration, wells were incubated with TMB solution containing enzyme-labeled goat anti-mouse antibody. After the formation of color by enzymatic reaction indicates the cell proliferation, the stop solution was added, and absorbance was recorded immediately by using a multiplate reader.

\section{Cell counting (trypan blue) assay}

Briefly, $5 \times 10^{4}$ prostate cancer cells were plated in each well of a 24-well plate. After properly adhering to the bottom surface, cells were exposed to dose-dependent $(10-10,000 \mu \mathrm{g} / \mathrm{ml})$ treatment with TA extract for 24 hours at $37^{\circ} \mathrm{C}$ in $5 \% \mathrm{CO}_{2}$ incubator. After the completion of the time point, the treated cells were harvested and stained with trypan blue dye. The dead cells were stained with trypan blue; however, live cells were easily counted by trypan blue exclusion test.

\section{Phase-contrast microscopy}

Phase-contrast microscopy was carried out to detect the change in cellular morphology of prostate cancer cells after dosedependent treatment with TA extract for 24 hours. Briefly, $0.5 \times$ $10^{6}$ were seeded per well of a 6-well plate and exposed to different doses of TA extract for 24 hours. After the completion of treatment, cells were analyzed by a phase-contrast microscope inbuilt with a camera to detect any change in the cellular morphology of cells.

\section{Detection of apoptosis by Terminal Transferase dUTP Nick End Labeling (TUNEL) assay}

Detection of the apoptotic population of prostate cancer cells after exposure to varying doses of TA extract for 24 hours was detected by the TUNEL assay apoptosis detection kit (Roche). After seeding, the LnCaP cells at a density of $5 \times 10^{5}$ per well on the sterile coverslips placed within the wells of the 6-well plate were incubated overnight in $5 \% \mathrm{CO}_{2}$ at $37^{\circ} \mathrm{C}$. After the completion of 
exposure time (24 hours) to various doses of TA extract $(67.5,125$, 250 , and $500 \mu \mathrm{g} / \mathrm{ml}$ ), cells grown on the coverslips were processed for fixation (4\% paraformaldehyde) and permeabilization (4\% Triton X-100) at room temperature for 10 minutes. Next, cells grown on the coverslips were incubated with a mixture of terminal deoxynucleotidyl transferase (TdT) and biotin-dUTP for 1 hour to label the blunt ends of double-stranded DNA breaks independent of substrate in cells undergoing apoptosis, followed by 30 minutes incubation with an avidin-FITC solution in the dark to tag the apoptotic cells which were green fluorescent compound for the detection and quantification. Subsequently, DAPI solution was added to stain the nucleus, which appears blue in color. After the completion of TUNEL staining, coverslips containing cells were put onto the clean grease-free glass slide and sealed the edges with nail polish to avoid any dryness of the slide. The glass slides were analyzed by confocal microscope (Zeiss LSM 710 META, Germany) for the detection of TUNEL-positive cells.

\section{Statistical analysis}

All the experiments in the current study were carried out at least three or more times. Statistical analysis of all the independent experiments was conducted by using GraphPad Prism software. The results obtained were expressed as mean \pm SEM. All the experiments were analyzed using one-way analysis of variance. Statistical significance was expressed as $p$-value, wherein the $p$-value of less than or equal to 0.05 was significant.

\section{RESULTS}

TA extract exhibits promising antiproliferative activity, induces apoptosis, and abrogates clonogenic properties in prostate cancer cells

We proposed to examine the antiproliferative potential of TA extract on the cellular growth of prostate cancer (PC-3, DU 145, LnCaP, C42B, and VCaP) cells and normal BPH cell line. The antiproliferative potential of TA extract was analyzed using the MTT assay to determine the percentage of cell viability. Our MTT results showed that TA extract could start inhibiting prostate cancer cell growth at a dose of $10 \mu \mathrm{g} / \mathrm{ml}$. Using GraphPad Prism software to evaluate the $\mathrm{IC}_{50}$ value of TA extract against a panel of prostate tumor cells, we observed the $\mathrm{IC}_{50}$ values of TA extract are $245,248,256,289$, and 273

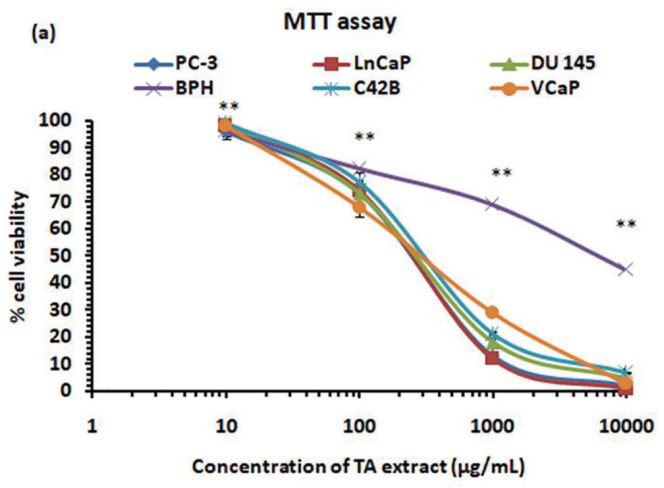

(c)

Trypan blue exclusion assay

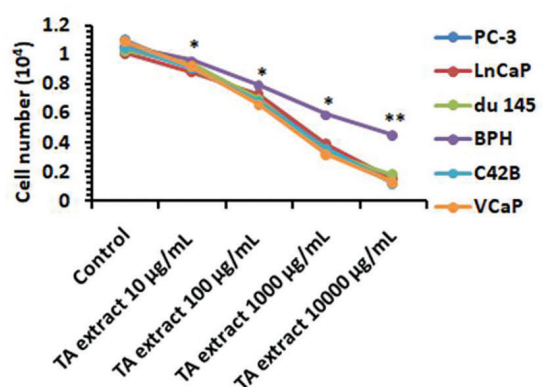

(d)
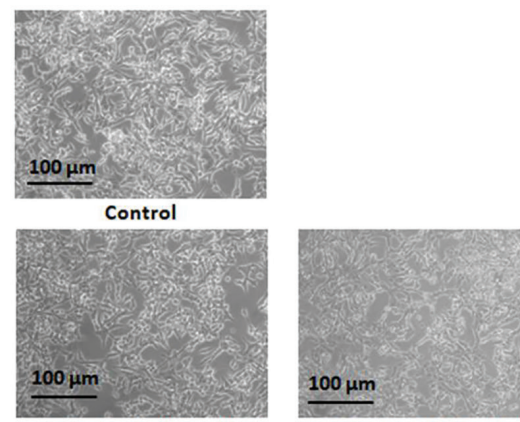

TA extract $67.5 \mu \mathrm{g} / \mathrm{mL}$

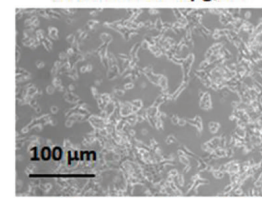

TA extract $250 \mu \mathrm{g} / \mathrm{mL}$

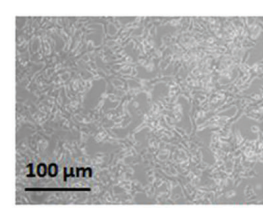

TA extract $125 \mu \mathrm{g} / \mathrm{mL}$

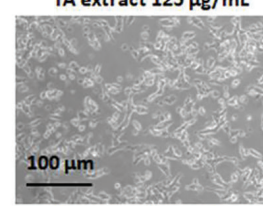

TA extract $500 \mu \mathrm{g} / \mathrm{mL}$

Figure 1. TA extract inhibits the cell proliferation of prostate cancer cells. (a) MTT assay showed a dose-dependent inhibition of prostate cancer cell panel (PC-3, LnCaP, DU 145, C42B, and $\mathrm{VCaP}$ ) and normal transformed prostate cells $(\mathrm{BPH})$ upon treatment with varying doses $(1,10,100,1,000$, and $10,000 \mu \mathrm{g} / \mathrm{ml})$ of TA extract for 24 hours. (b) Brd U incorporation assay to determine cell proliferation of prostate cancer cells after exposure to different doses of TA extract for 24 hours. (c) Trypan blue exclusion assay to determine the cell viability of prostate cancer cells after varying treatments of TA extract for 24 hours. (d) Phase-contrast microscopy to analyze changes in cellular morphology of prostate cancer cells (LnCaP) after treatment with different doses of TA extract $(67.5,125,250$, and $500 \mu \mathrm{g} / \mathrm{ml})$ for 24 hours. The representation of data is the mean value of $\pm \mathrm{SE}$ of three or more than three independent experiments with statistical significance equal to $* p<0.05 ; * p<0.01$. 

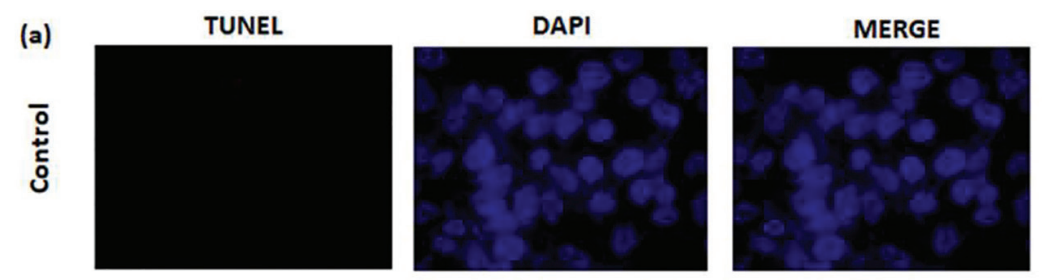

(b)
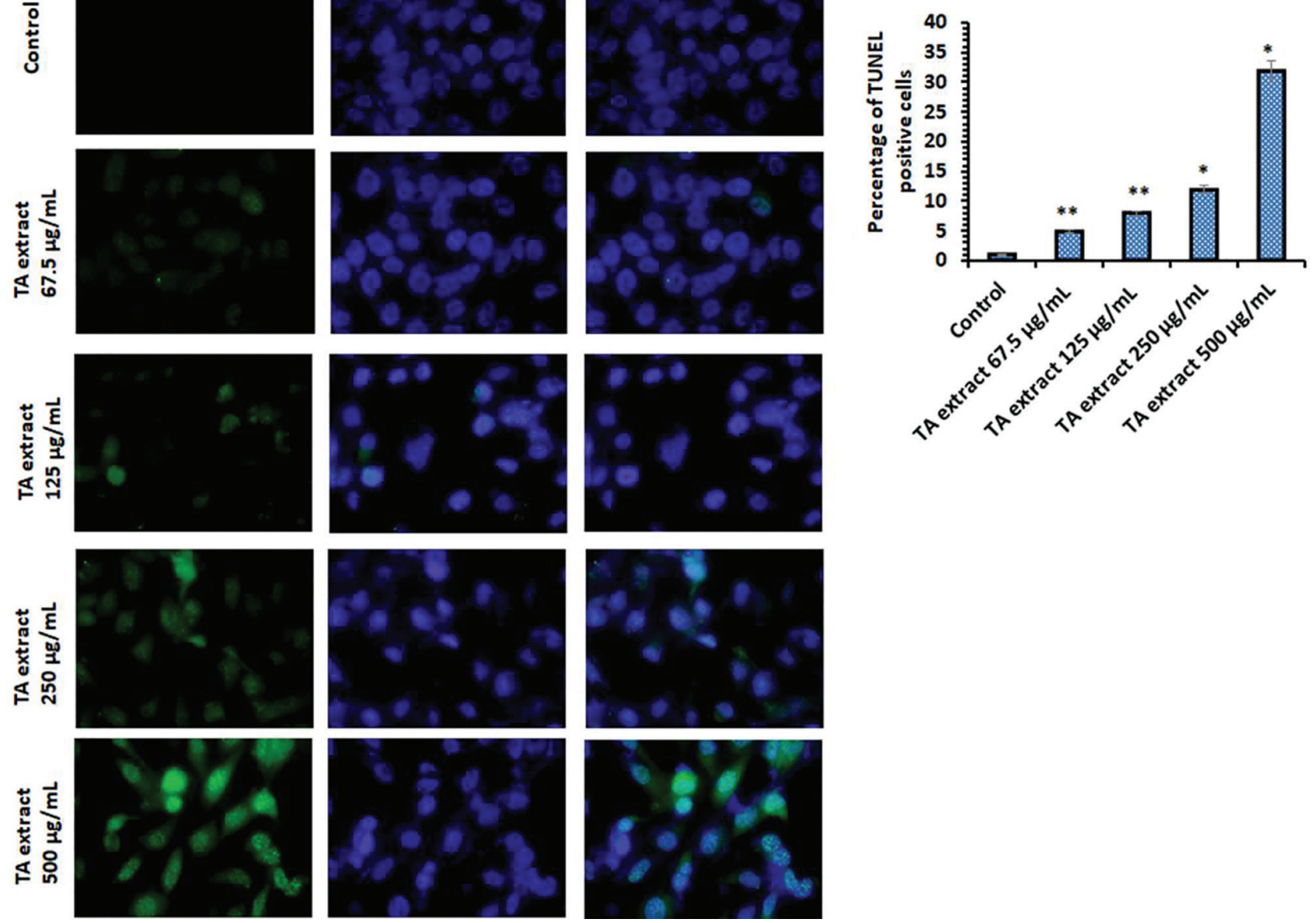

Figure 2. TA extract promotes apoptotic mode of cell death in prostate cancer (LnCaP) cells. (a) Visualization of TUNEL assay staining of apoptotic $\mathrm{LnCaP}$ cells after exposure to varying doses of TA extract $(67.5,125,250$, and $500 \mu \mathrm{g} / \mathrm{ml})$ for 24 hours. (b) Histogram represents the percentage of TUNEL-positive cells after exposure to varying doses of TA extract $(67.5,125,250$, and $500 \mu \mathrm{g} / \mathrm{ml})$ for 24 hours. The representation of data is the mean value of $\pm \mathrm{SE}$ of three or more than three independent experiments with statistical significance equal to $* p<0.05$ and ${ }^{* *} p<0.01$.

$\mu \mathrm{g} / \mathrm{ml}$ against LnCaP, PC-3, DU 145, C42B, and VCaP cells, respectively (Fig. 1a). Intriguingly, we observe a significantly high $\mathrm{IC}_{50}$ value $(9,541 \mu \mathrm{g} / \mathrm{ml})$ of normal $\mathrm{BPH}$ cells when exposed to varying doses of TA extract. This indicates that TA extract attenuates prostate tumor cell growth specifically and exhibits a safe level of toxicity against normal transformed cells (BPH). To further confirm the antiproliferative potential of TA extract, we carried out Brd $U$ incorporation and trypan blue exclusion assays. Our results showed that a significant reduction of Brd $\mathrm{U}$ incorporation (a thymidine analog) (*p< $0.05 ; * * p<0.01$ ) (Fig. 1b) and viability of cells by trypan blue exclusion assay $(* p<0.05 ; * * p<0.01$ ) (Fig. 1c) were observed after prostate cancer cells were exposed to varying doses of TA extract for 24 hours. Moreover, phase-contrast microscopy of LnCaP cells after dose-dependent treatment with TA extract $(67.5,125,250$, and $500 \mu \mathrm{g} / \mathrm{ml})$ for 24 hours reveals a prominent change in morphology of cells in treated cells compared to untreated control. The alteration in morphology was maximum at the higher doses of TA extract treatment (Fig. 1d).

We next intended to evaluate whether the TA extract induced antiproliferative effect in prostate cancer cells is due to apoptosis. To do so, we carried out a TUNEL assay. After the dose-dependent exposure of LnCaP cells to TA extract $(67.5,125$, 250 , and $500 \mu \mathrm{g} / \mathrm{ml}$ ) for 24 hours, cells in all treatments including untreated control were incubated with a mixture of TdT and biotin-dUTP, followed by avidin-FITC for 30 minutes and nuclear staining (DAPI) in the dark.

Our results showed that the number of TUNEL-positive cells increases as the treatment dose of TA extract increases (Fig. 2a). The maximum number of TUNEL-positive cells was observed $32 \%(* p<0.05)$ when exposed to $500 \mu \mathrm{g} / \mathrm{ml}$, followed by $11 \%(* p<0.05)$ at $250 \mu \mathrm{g} / \mathrm{ml}, 7 \%(* * p<0.01)$ at $125 \mu \mathrm{g} / \mathrm{ml}$, and $5 \%(* * p<0.01)$ at $67.5 \mu \mathrm{g} / \mathrm{ml}$ dose of TA extract compared to untreated control (Fig. 2b). Collectively, these results suggest that TA extract induces cell death of prostate cancer cells by apoptosis mechanism, and the effect is promising at higher doses of TA extract.

Additionally, we intended to evaluate whether the clonogenic property of prostate cancer cells was also attenuated using TA extract. Our results revealed that subtoxic doses of TA extract treatment lasting 24 hours significantly reduce the ability of $\mathrm{LnCaP}$ cells to form colonies at higher doses of TA extract when compared to untreated control. Further, the anticlonogenic 


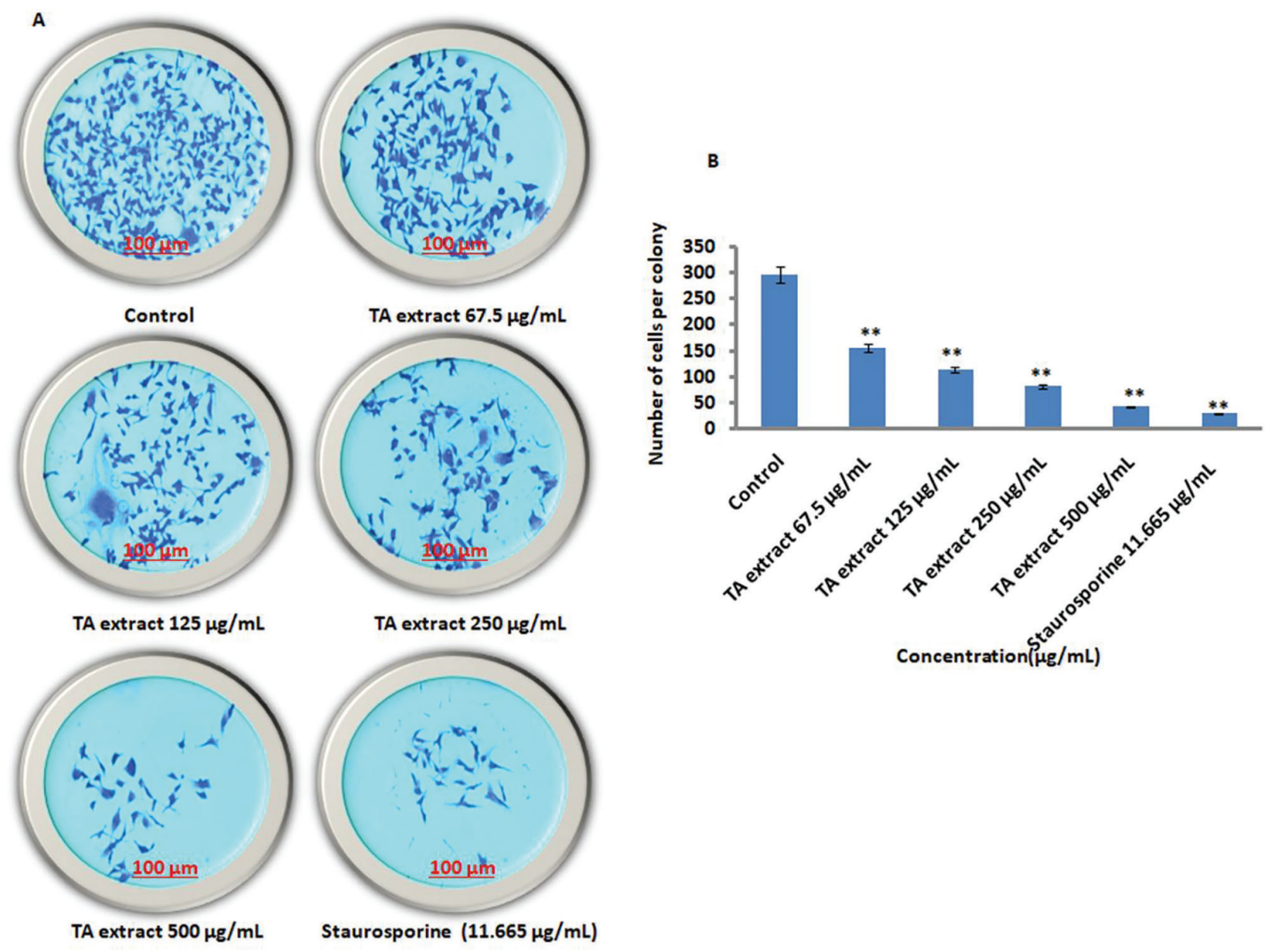

Figure 3. TA extract attenuates the clonogenic property of prostate cancer cells. (A) The treatment of prostate cancer cells (LnCaP) with varying doses of TA extract along with untreated control and positive control staurosporine for 24 hours to evaluate the anticolony formation activity of TA extract. The scale bar is $100 \mu \mathrm{m}$ with $10 \times$ magnification. (B) The bar diagram represents the quantification of prostate cancer (LnCaP) cells per colony per field following treatment with varying doses of TA extract $(67.5,125,250$, and $500 \mu \mathrm{g} / \mathrm{ml})$ for 24 hours. The representation of data is the mean value of $\pm \mathrm{SE}$ of three or more than three independent experiments with statistical significance equal to ${ }^{* *} p<0.01$.

effect of TA extract at a high concentration $(250 \mu \mathrm{g} / \mathrm{ml})$ was as good as that of positive control staurosporine $(11.663 \mu \mathrm{g} / \mathrm{ml})$ (Fig. 3a, b).

\section{TA extract abolishes migration, motility, and invasive property of prostate cancer ( $\mathrm{LnCaP})$ cells}

To evaluate whether TA extract could also abrogate the motility, migration, and invasive property of prostate malignant cells under in vitro settings, the antimetastatic activity after exposing $\mathrm{LnCaP}$ cells to TA extract was evaluated by the wound healing assay. Owing to the high percentage of cell death at higher doses of TA, the subtoxic doses $(67.5,125$, and $250 \mu \mathrm{g} /$ $\mathrm{ml}$ ) of TA extract for 24 hours were intelligently selected to nullify any biased antimetastatic effect (Rah et al., 2012) at high dose $(500 \mu \mathrm{g} / \mathrm{ml})$ of TA extract when the antimotility evaluation was carried out on LnCaP cells. Our wound-healing results demonstrated a significant decline in cell migration and motility was observed when $\mathrm{LnCaP}$ cells were exposed to 125 and 250 $\mu \mathrm{g} / \mathrm{ml}$ of TA extract (Fig. 4a, b) compared to untreated DMSO control, which was almost filled with cells migrated from adjacent areas. Further, the antimigration effect of $250 \mu \mathrm{g} / \mathrm{ml}$ of TA extract was statistically significant when compared to positive control camptothecin $(2 \mu \mathrm{M})$.

To evaluate whether TA extract could have an inhibitory impact on the invasive property of prostate malignant cells, we carried out the Transwell Boyden chamber assay to determine whether TA extract attenuates the prostate cancer cell migration through the porous Matrigel membrane of the upper insert of the Transwell Boyden chamber. We observe that a substantial number of invasive cells fail to infiltrate via porous Matrigel membrane at higher doses of TA extract compared to untreated control (Fig. 5a). Additionally, our histogram analysis revealed that the number of invasive cells is 77,58 , and 28 at a dose of $67.5,125$, and $250 \mu \mathrm{g} / \mathrm{ml}$ of TA extract, respectively, when compared to 149 invasive prostate malignant cells in the untreated control (Fig. 5b). Further, the high dose $(250 \mu \mathrm{g} / \mathrm{ml})$ of TA extract attenuates invasion of prostate cancer ( $\mathrm{LnCaP})$ cells through the Matrigel membrane as effectively as that of positive control camptothecin $(2 \mu \mathrm{M})$. Together, these findings demonstrate that TA extract inhibits the cellular motility, migration, and invasion of prostate cancer $(\mathrm{LnCaP})$ cells significantly. Furthermore and equally importantly, the 
(a)
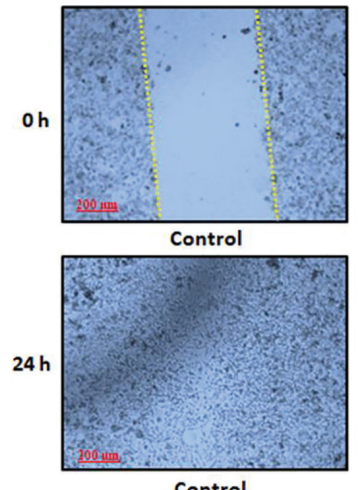

Control

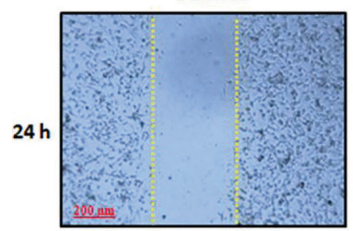

TA extract $250 \mu \mathrm{g} / \mathrm{mL}$

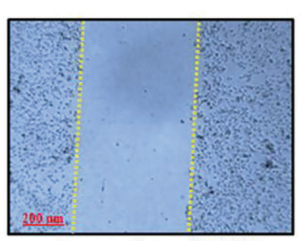

Camptothecin $(2 \mu \mathrm{M})$

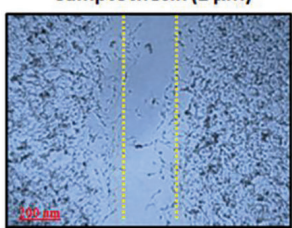

TA extract $125 \mu \mathrm{g} / \mathrm{mL}$ (b)
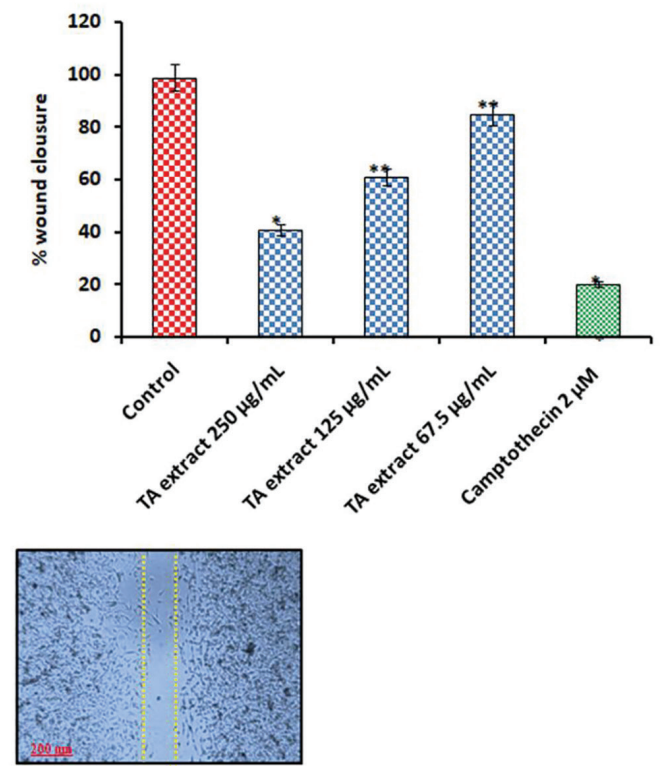

TA extract $67.5 \mu \mathrm{g} / \mathrm{mL}$

Figure 4. TA extract abrogates the cell migration of prostate cancer cells. (a) Prostate cancer cells (LnCaP) were exposed to indicate concentrations of TA extract $(67.5,125$, and $250 \mu \mathrm{g} / \mathrm{ml})$ along with untreated control and positive control camptothecin $(2 \mu \mathrm{M})$ for 24 hours to determine the motility of cells. The scale bar is $100 \mu \mathrm{m}$ with $10 \times$ magnification. (b) The bar diagram represents the percentage of wound closure of prostate cancer ( $\mathrm{LnCaP}$ ) cells in control and in wells treated with varying doses of TA extract $(67.5,125,250$, and $500 \mu \mathrm{g} / \mathrm{ml})$ for 24 hours. The representation of data is the mean value of $\pm \mathrm{SE}$ of three or more than three independent experiments with statistical significance equal to $* * p<0.01$.

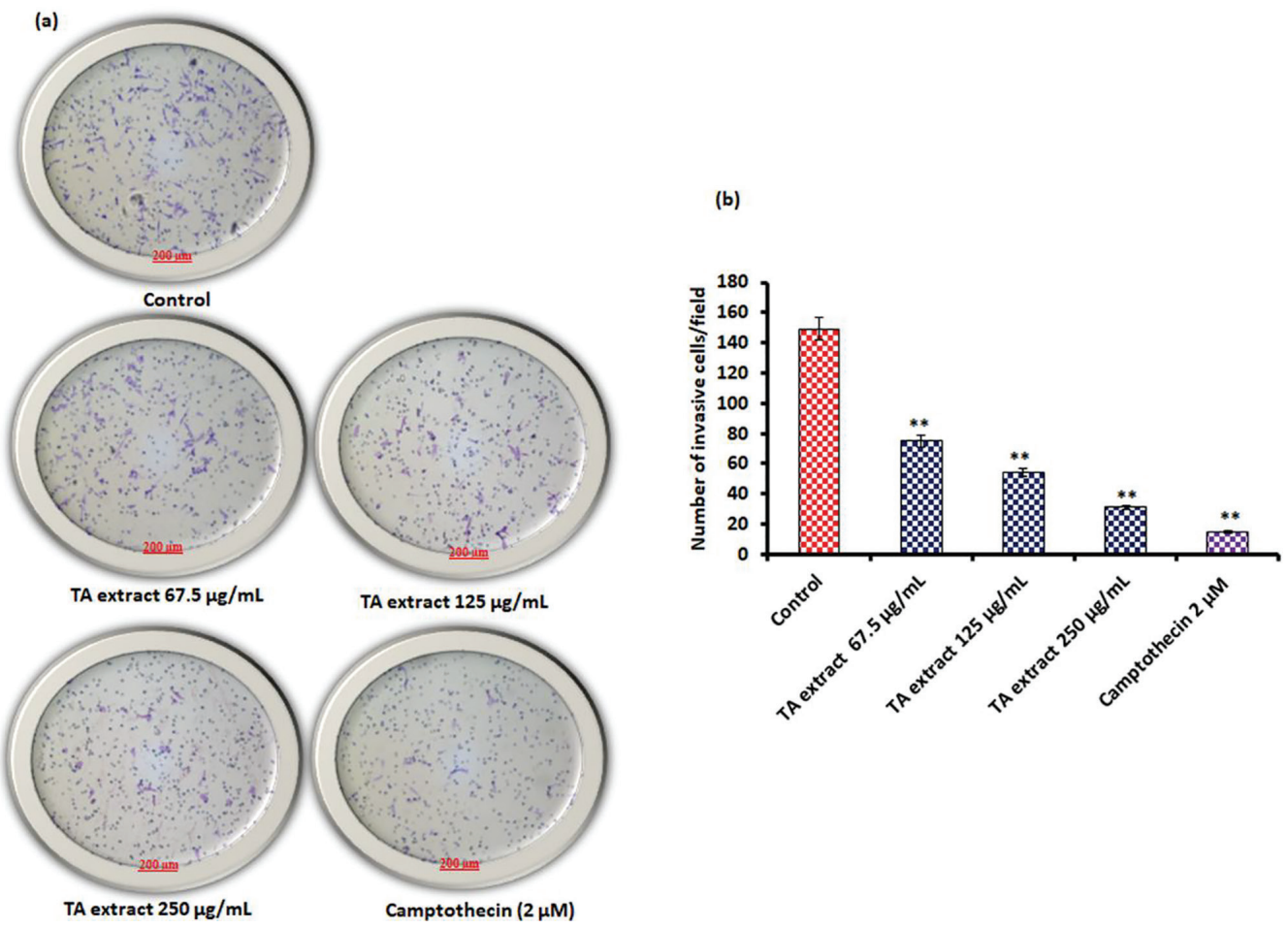

Figure 5. TA extract inhibits the cell invasion property of prostate cancer $(\mathrm{LnCaP})$ cells. (a) $\mathrm{LnCaP} 2 \times 105$ cells were seeded in the upper insert of the Transwell Boyden chamber and simultaneously indicated that doses of TA extract $(67.5,125,250$, and $500 \mu \mathrm{g} / \mathrm{ml})$ were added along with untreated control and positive control camptothecin $(2 \mu \mathrm{M})$ for 24 hours to evaluate the anti-invasive potential of TA extract. The scale bar is $100 \mu \mathrm{m}$ with $10 \times$ magnification. (b) The bar diagram represents the number of invaded prostate cancer ( $\mathrm{LnCaP})$ cells across the porous Matrigel membrane in control and in upper inserts treated with varying doses of TA extract $(67.5,125,250$, and $500 \mu \mathrm{g} / \mathrm{ml})$ for 24 hours. The representation of data is the mean value of $\pm \mathrm{SE}$ of three or more than three independent experiments with statistical significance equal to ${ }^{* *} p<0.01$. 
(a)

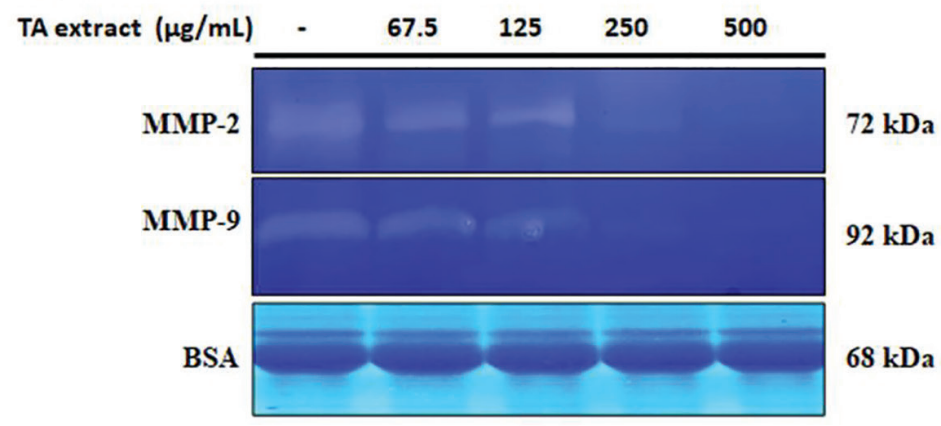

(c)

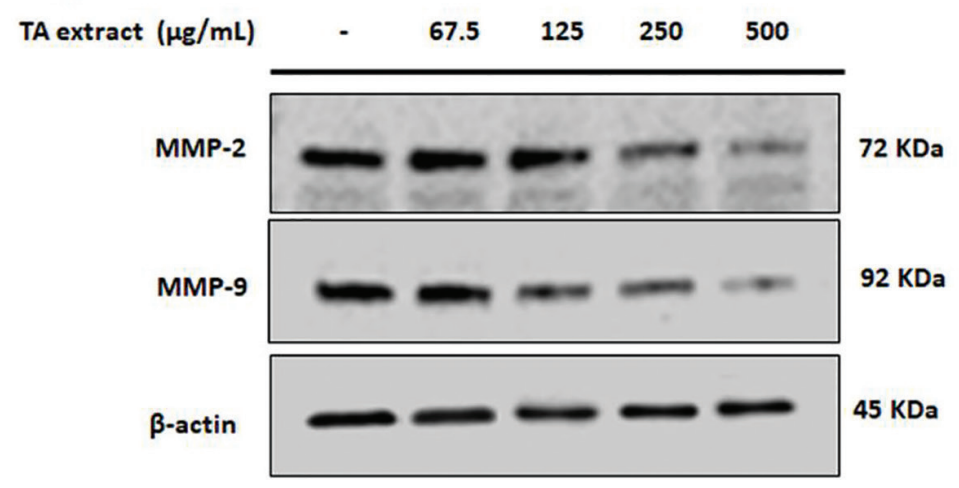

(b)

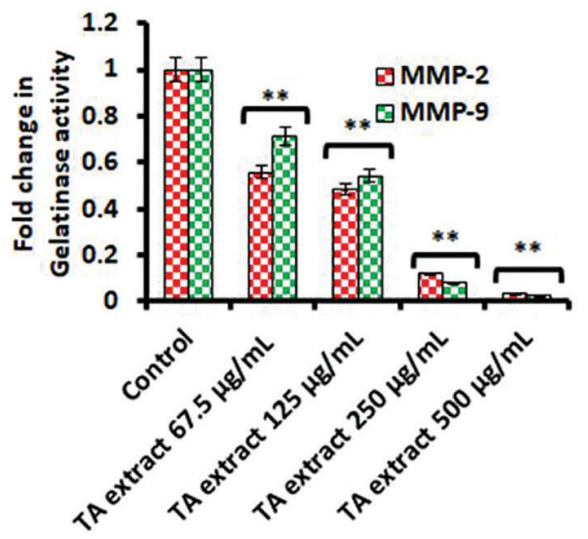

(d)

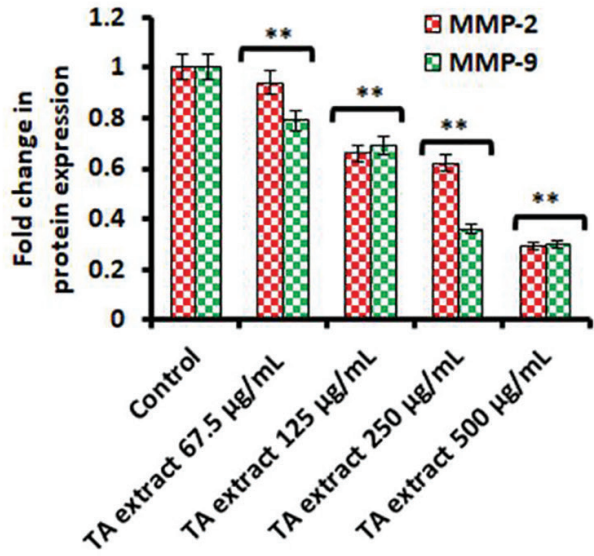

Figure 6. TA extract abrogates the MMP-2/9 activity and expression in prostate cancer (LnCaP) cells. (a) The gelatinase activity of MMP-2, MMP9, and loading control BSA in conditional media samples collected from separate wells of cells exposed to varying doses of TA extract along with untreated control for 24 hours. (b) The representative histograms show gelatinase activity (fold change) in conditional media samples exposed to varying doses of TA extract. (c) Protein expression of MMP-2/9 and an internal loading control in conditional media samples exposed to indicate doses of TA extract along with untreated control for 24 hours. (d) Fold change in protein expression of MMP-2/9 after being normalized with internal control $\beta$-action by densitometry analysis. The representation of data is the mean value of $\pm \mathrm{SE}$ of three or more than three independent experiments with statistical significance equal to $* * p<0.01$.

antimetastatic activity of TA extract at a high dose is as effective as that of positive control camptothecin.

TA Abrogates matrix metalloproteins MMP-2/9 activity as well as expression in prostate cancer ( $\mathrm{LnCaP})$ cells

Further, we intended to evaluate whether TA extract could exhibit anti-MMPs activity secreted by LnCaP cells. We observe a prominent decrease in MMPs activity (MMP-2/9) by zymography in the conditional media samples collected after exposure to varying doses of TA extract for 24 hours (Fig. 6a, b). To evaluate whether TA extract downregulates the expression of MMPs at the translation level, we carried out immunoblotting of LnCaP cells exposed to varying doses of TA extract for 24 hours. Our immunoblotting results also revealed that there is a significant downregulation in the expression of MMP-2/9 proteins at higher doses of TA extract compared with untreated control (Fig. 6c, d). Together, these findings suggest that larger doses of TA effectively abrogate activity.
TA extract exerts antimetastatic effect by modulating PI3KAkt, and TGF- $\beta$ pathways and their downstream targets in prostate cancer ( $\mathrm{LnCaP})$ cells

We intended to explore whether TA extract could inhibit PI3K-Akt signaling in prostate cells. As displayed in Figure 7a, b, our Western blotting analysis of $\mathrm{LnCaP}$ cell lysates treated with varying doses $(67.5,125,250$, and $500 \mu \mathrm{g} / \mathrm{ml})$ of TA extract inhibits phosphorylation of PI3K-P110 $\alpha$ protein in a dose-dependent way. To evaluate whether the TA extract can also modulate the downstream mediators of PI3K-Akt signaling, our Western blotting results demonstrated a significant downregulation of phosphorylated p-Akt-Ser-473. This was evident when prostate malignant cells were exposed to higher doses of TA extract for 24 hours. Further, we did not observe any significant change in the expression of total Akt in the same samples. To explore whether TA extract could also attenuate the TGF- $\beta$-mediated epithelialmesenchymal transition (EMT) associated metastasis in prostate cancer. We expose LnCaP cells to dose-dependent treatment of 
(a)

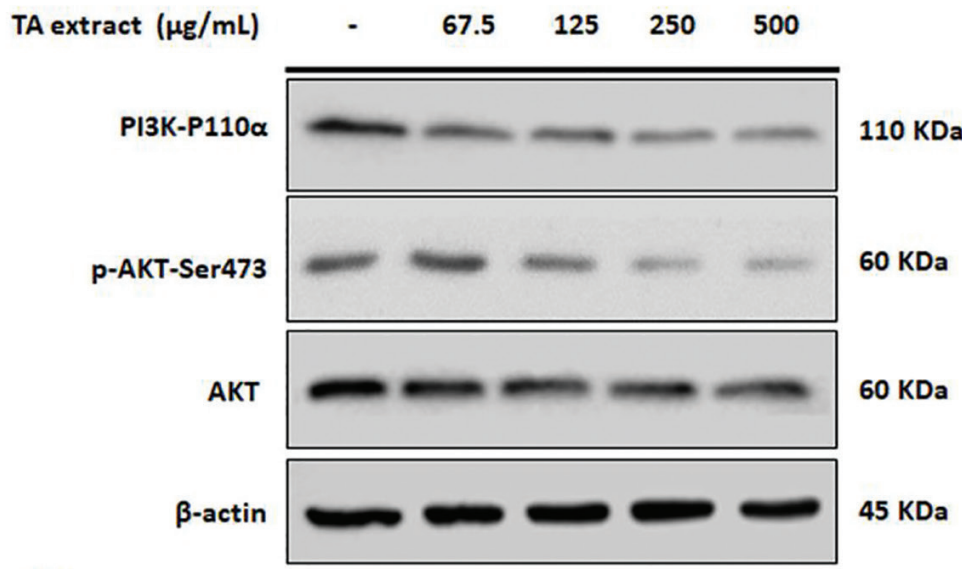

(c)

TA extract $(\mu \mathrm{g} / \mathrm{mL}) \quad-\quad 67.5 \quad 125 \quad 250 \quad 500$

(e)

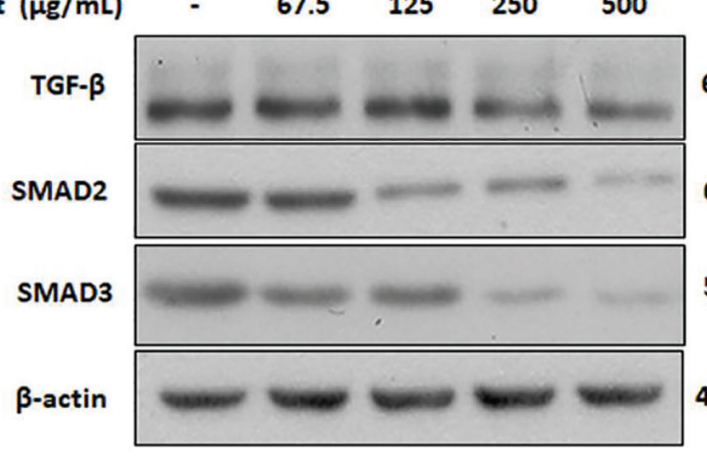

$65 \mathrm{KDa}$

$60 \mathrm{KDa}$

$52 \mathrm{KDa}$

$45 \mathrm{KDa}$

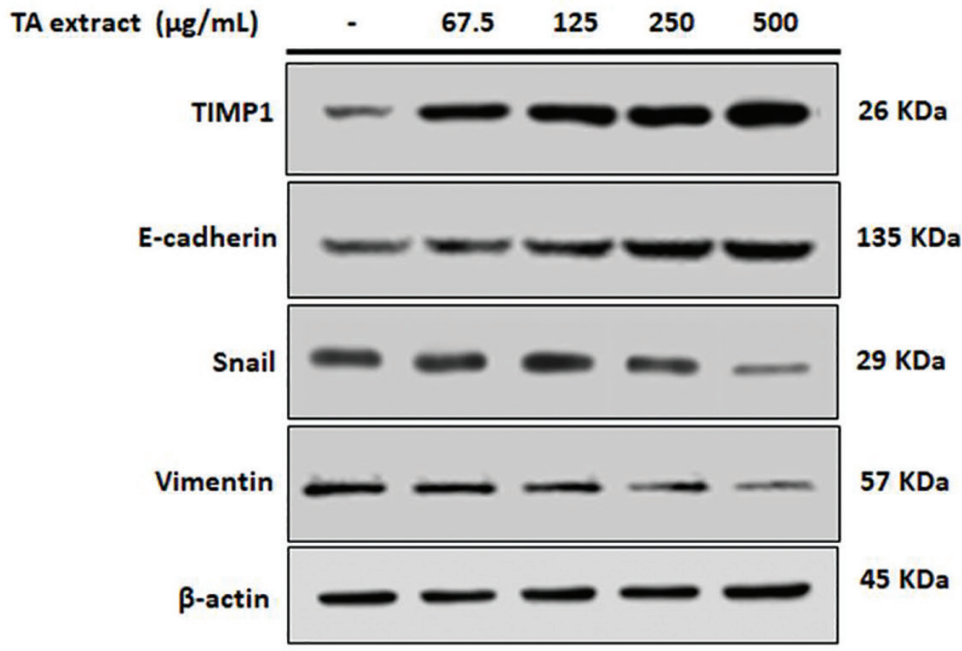

(b)

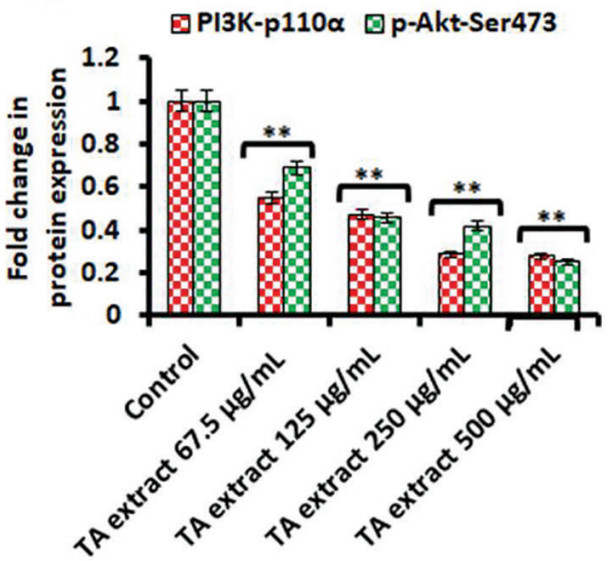

(d)
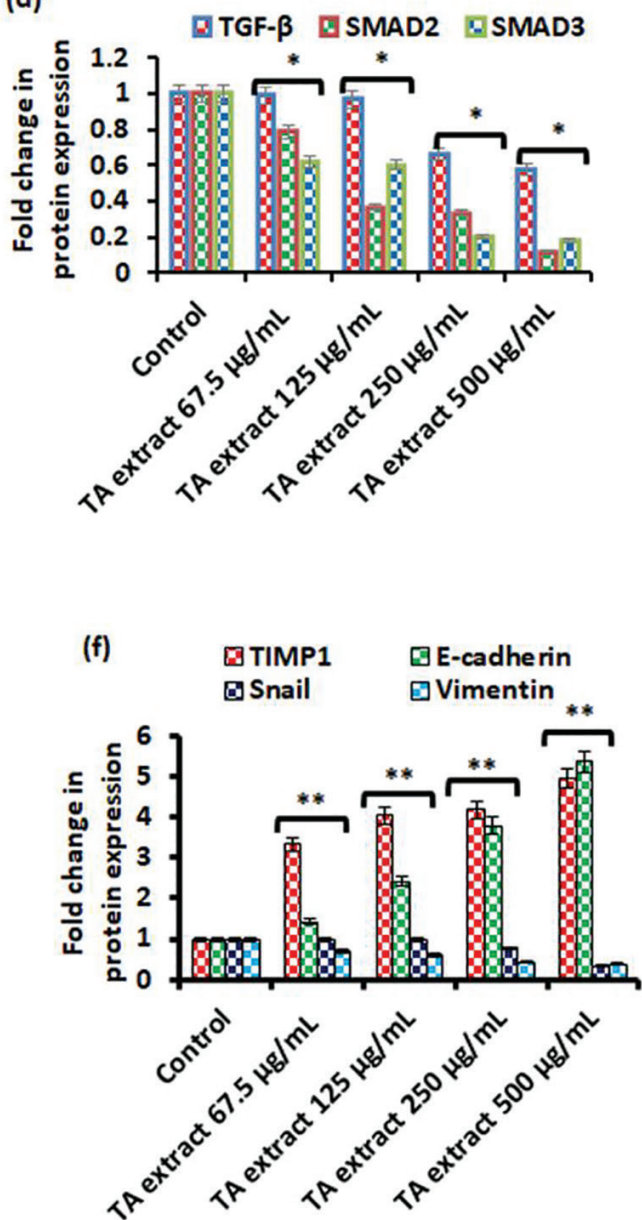

Figure 7. Modulation of PI3K-Akt signaling and its downstream targets by TA extract in prostate cancer cells. (a) Protein expression by Western blotting of prostate cancer $(\mathrm{LnCaP})$ cells after treatment with varying doses of TA extract $(67.5,125$, and $250 \mu \mathrm{g} / \mathrm{ml})$ indicates the change in expression of PI3KP110 $\alpha$, Akt, p-Akt-Ser473, and an internal control $\beta$-action. (b) Fold change in protein expression of PI3K-P110 $\alpha$ and p-Akt-Ser473 after being normalized with internal control $\beta$-action by densitometry analysis. (c) Protein expression by Western blotting of prostate cancer (LnCaP) cells after treatment with varying doses of TA extract $(67.5,125$, and $250 \mu \mathrm{g} / \mathrm{ml})$ indicates the change in expression of TGF- $\beta$, SMAD2, SMAD3, and an internal control $\beta$-action. (d) Fold change in protein expression of TGF- $\beta$, SMAD2, and SMAD3 after being normalized with an internal control $\beta$-action by densitometry analysis. (e) Protein expression by Western blotting of prostate cancer cells $(\mathrm{LnCaP})$ after treatment with varying doses of TA extract in the presence of untreated control indicates the change in expression of TIMP1, E-cadherin, snail, vimentin, and an internal control $\beta$-action. (f) Fold change in protein expression of TIMP1, E-cadherin, snail, and vimentin after being normalized with internal control $\beta$-action by densitometry analysis. The representation of data is the mean value of $\pm \mathrm{SE}$ of three or more than three independent experiments with statistical significance equal to $* p<0.05 ; * * p<0.01$. 
TA extract $(67.5,125,250$, and $500 \mu \mathrm{g} / \mathrm{ml})$ for 24 hours. Our immunoblotting results revealed that the TA extract downregulates the expression of TGF- $\beta$ and its downstream mediators SMAD2 and SMAD3 in a dose-dependent manner (Fig. 7c, d). Further, to investigate whether TA extract-mediated downregulation of PI3KAkt and TGF- $\beta$-SMAD2/3 signaling pathways could have any impact on MET, which are the key mediators in cell migration and invasion, we expose prostate malignant $(\mathrm{LnCaP})$ cells to varying doses of TA extract $(67.5,125,250$, and $500 \mu \mathrm{g} / \mathrm{ml})$ for 24 hours. Through immunoblotting experiments, we observe a prominent decline in the expression of MET proteins snail and vimentin with simultaneous induction in the protein expression of E-cadherin and TIMP1 at higher doses of TA extract (Fig. 7e, f). Together, these findings suggest that TA extract mitigates PI3K-Akt and TGF- $\beta$-SMAD2/3 stimulation and subsequently does not transmit a signal downstream associated proteins snail and vimentin that are regulating tumor cell invasion in prostate cancer cells.

\section{DISCUSSION}

Previous reports documented that numerous plant extracts exhibit an antiproliferative effect against a variety of tumor cell models (Kaur et al., 2009; Sreelatha et al., 2011). Our preliminary published work also revealed the inhibition of tumor cells (breast and colorectal) by TA extract (Alnuqaydan and Rah, 2020). TA displayed antitumor activity by modulating miRNA-1275 which plays a crucial role in the development of tumorigenesis (Shaalan et al., 2018). The current investigation discovered that TA extract promotes antiproliferative, anticlonogenic, antimigratory, and antiinvasive activity against prostate malignant cells. Mechanistically, TA extract modulates PI3K-Akt and TGF- $\beta$-SMAD2/3 signaling in prostate cancer cells for 24 hours. Further, TA extract downregulates its downstream signaling mediators MMP-2/9 and MET-associated proteins snail, vimentin with concomitant upregulation of TIMP1, and E-cadherin after treating cells for 24 hours. These observations revealed that TA extract could be the main source of promising anticancer agents to prevent prostate tumorigenesis in the future.

Numerous plants and derived products possess various phytochemicals that exhibit potential pharmacological properties such as anti-inflammatory, antidiabetic, and anticancer. Consequently, these plants and their derived products can act as a crucial source for drugs against various diseases, including cancer, with less deleterious effects on transformed normal cells (BPH cells) (Cassady et al., 1990). To date, approximately 50\% of food and drug administration-approved drugs are directly extracted from either plants or their products (Patridge et al., 2016). The in vitro cellular models and preclinical studies have revealed that a significant number of plant species have still not been evaluated for their phytochemical characteristics, even though they potentially exhibit promising pharmacological activity with great efficacy and fewer toxicity issues. TA is one such plant from Saudi Arabia which has not been evaluated completely for its pharmacological analysis. However, there are some reports that TA extract displays some pharmacological activities such as anti-inflammatory, antioxidative, hepatoprotective, and antitumor activity in some tumor cell lines. The phytochemical analysis of the methanolic extract of TA by LC-MS analysis reveals the identification of some major compounds such as solenopsin, ailanthone, dicumarol, dronabinol, oxymatrine, quercetin, resveratrol, and rottlerin (Supplementary Fig. 1; Supplementary Table 1) which exhibit anticancer properties such as immunomodulation, antiinflammatory activity, antifertility activity, apoptosis and induction of autophagy, and ROS-mediated mitochondrial-dependent apoptosis to kill malignant cells.

Previous reports suggest that a mixture of phytochemicals in plant extracts exhibits a wide range of pharmacological activities due to the synergistic or additive effect of key phytochemicals in the extract (Efferth, 2017; Kapinova et al., 2017; Phan et al., 2018; Rather et al., 2013). Consistent with these findings, the antiproliferative and antimetastatic activities of the TA extract are probably due to the synergistic interaction of major phytochemicals with other compounds in the extract. Our initial experiments demonstrated that TA extracts exhibit promising cytotoxic activity by significantly reducing the viability of prostate cancer cells. Additionally, we observed an incredibly low cytotoxic effect of TA extract at the same dose and time against normal BPH cells. Furthermore, we found that $50 \%$ of the cell populations of $\mathrm{BPH}$ cells were killed at a dose $\left(\mathrm{IC}_{50}=9,541 \mu \mathrm{g} / \mathrm{ml}\right)$ by TA extract, which is a significantly much higher dose. Additionally, the antiproliferative activity of TA extract against a panel of prostate cancer cells was also supported by Brd U incorporation and trypan blue exclusion assays. The phase-contrast microscopy to analyze morphological changes further demonstrates the dose-dependent antiproliferative effect of TA extract. Additionally, our results suggest that TA extract has the potential for anticolony formation and can fight against prostate ( $\mathrm{LnCaP}$ ) cancer cells. Together, these findings demonstrate that TA extract has a promising antiproliferative effect that specifically promotes the death of prostate cancer cells and also possesses insignificant cytotoxicity against normal BPH cells with a safe toxicity profile.

Buranrat et al. (2020), revealed that Oroxylum indicum extracts displayed promising antiproliferative effects against breast adenocarcinoma cells by modulating the expression of Rac1 signaling. Furthermore, the study reveals that downregulation of Rac1 expression abrogates adenocarcinoma cell migration and abolishes both MMP-9 activity and protein expression in breast cancer cells (Buranrat et al., 2020). A similar study revealed that a significant attenuation of hepatocyte growth factor-mediated cell invasion and migration of prostate cancer cells was observed in Boswellia frereana extract at higher doses. Furthermore, the analysis confirmed that $B$. frereana extract-mediated abrogation of prostate cell migration and invasion was due to modulation of c-Met signaling (Parr and Ali, 2018). The crucial step in metastasis is for the tumor cells to use a cascade of oncogenic mutations in order to invade or cross various physical barriers and spread to distant secondary sites (Björklund and Koivunen, 2005; Kumar and Weaver, 2009). Consistent with these previous studies, we observe that TA extract displays a considerable decrease in the cell motility of prostate cancer cells. To address any rational discrimination of TA extract in controlling the migration property of tumor cells with apoptosis, we carefully chose the concentrations of TA extract that are not lethal to cells. TUNEL assay results suggest that $125 \mu \mathrm{g} / \mathrm{ml}$ of TA extract does not promote significant cell death $(7 \%)$, yet the same dose could modulate the migration of prostate cancer cells significantly to that of untreated control cells placed in a 6-well plate which was significantly occupied with 


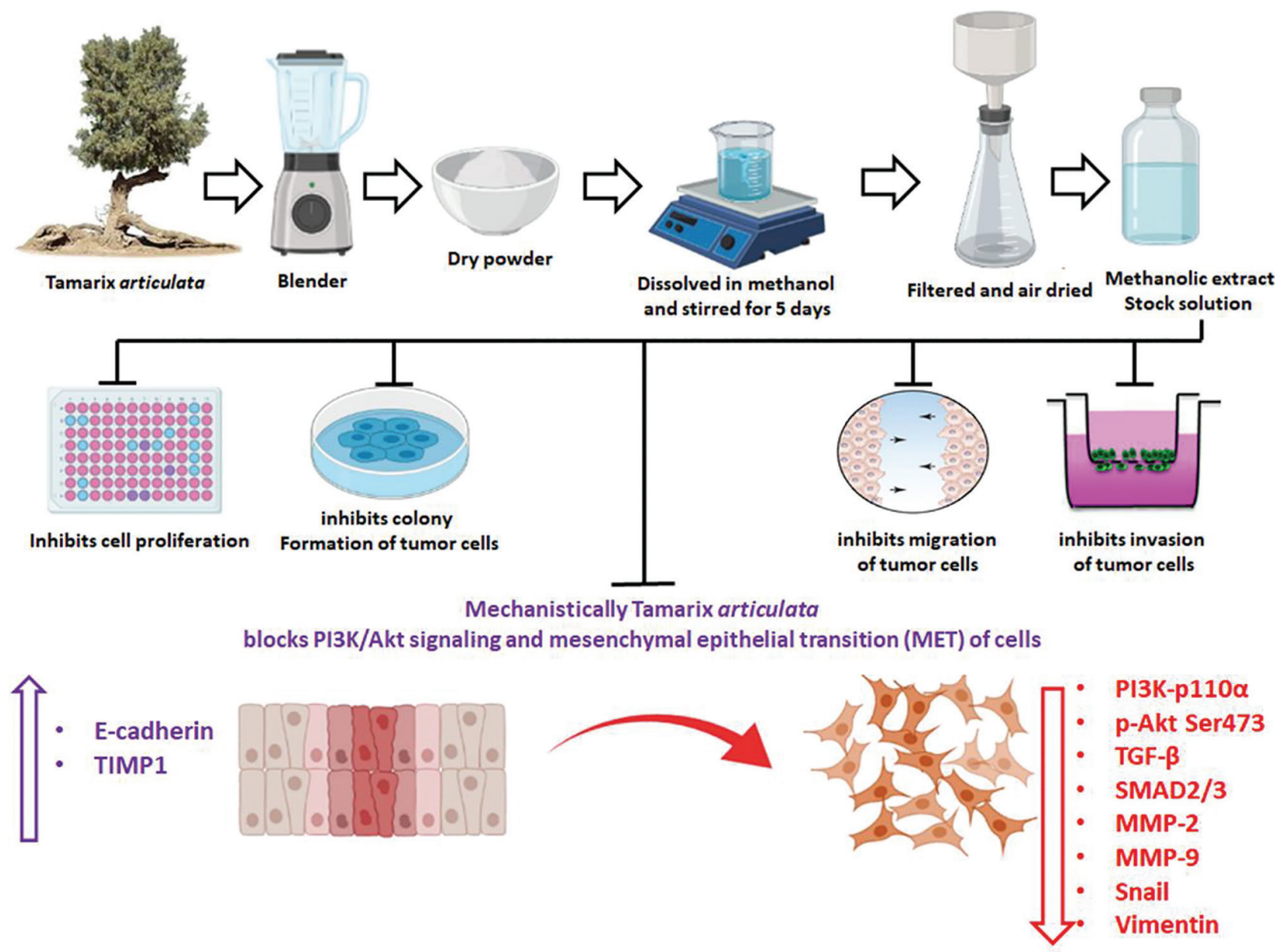

Figure 8. Schematic diagram showing the stages of methanolic extraction of TA and how it exerts antiproliferative, antimotility, anti-invasive effects, and possible antimetastatic mechanism against prostate $(\mathrm{LnCaP})$ cancer cells.

migrated cells. The striking feature of metastasis is the ability to disseminate malignant cells to distant secondary sites by crossing various physical barriers such as the extracellular basement matrix (Fares et al., 2020). Our results support the view that sublethal concentrations of TA extract considerably impede several tumor cells to display excellent antimigration properties against prostate cancer cells which possess the ability to infiltrate a perforated Matrigel-coated membrane.

Metastasis is a cascade of a complex process that includes cell invasion, motility migration, and last but not least, the activation and upregulation of MMPs. This functions to break the physical barrier in the form of the basement membrane and allow malignant cells to spread to distinct sites from the primary tumor site. Previous reports suggest that significantly high expression of MMPs has been implicated in metastasis (Dinicola et al., 2014; Hwang et al., 2006), and various herbal remedies are able to attenuate the expression as well as activity of matrix metalloproteinase. Consistent with these findings, our results revealed that a significant antimetastatic activity was displayed by TA extract against prostate malignant cells by abrogating both expression and activity of MMP-2/9 at the translational level, which plays an important role in metastasis.
Previous reports suggest that there is a strong correlation of deregulated PI3K-Akt signaling pathway activation due to frequent phosphatase and tensin homolog mutation in prostate cancer cells and performs a vital role in cell migration, invasion, and motility of malignant cells (Sarker et al., 2009; Shukla et al., 2007). Accumulating evidence demonstrates that aberrant PI3KAkt-mediated signaling plays a crucial role in tumor cell growth. Recent reports suggest that the PI3K-Akt pathway-mediated cell migration and invasion in various types of solid malignancies to distant sites occurred through various downstream mediators (Altomare and Testa, 2005; Saji and Ringel, 2010). Moreover, recent reports suggest a strong correlation between the PI3KAkt and associated signaling pathway with cancer cell migration, invasion, metastasis, and development of chemotherapeutic drug resistance (Singh et al., 2013; Vara et al., 2004). The PI3K-Akt pathway and its downstream mediators play a critical role in transferring and augmenting extracellular signaling to intracellular adapter proteins in prostate malignant cells and modulate cellular processes in favor of tumor growth (Rasool et al., 2016). In our study, we observe that TA extract downregulates the phosphorylation of the PI3K-Akt signaling pathway in prostate cancer cells. The TGF- $\beta$ signaling pathway is well documented 
to play a critical role in tumorigenesis and metastasis (Katsuno et al., 2013). Previous reports suggest that TGF- $\beta$ pathway regulates laminin, collagen, and fibronectin, and MMP-9 thereby modulates invasive and migratory ability of tumor cells (Margadant and Sonnenberg, 2010). The TGF- $\beta$ signaling pathway plays a major role in EMT and metastasis of prostate cancers cells (Katsuno et al., 2013). Accumulating evidence revealed that various herbal medicines such as anthocyanidins, thymoquinone, and curcumin abrogate EMT and attenuate metastasis by downregulating TGF$\beta$-SMAD2/3 signaling (Kou et al., 2017; Zhang et al., 2016). Consistent with previous findings, our results revealed a dosedependent downregulation of TGF- $\beta$-SMAD2/3 expression upon treatment of LnCaP cells with TA extract for 24 hours. Additionally, recent study revealed that various cytokine receptors such as TGF- $\beta$ further augment the dysregulation of PI3K-Akt signaling, which in turn drives cells towards metastasis by pushing them towards EMT to MET (Jothimani et al., 2020). To evaluate whether TA extract could have any impact on these PI3K-Akt and TGF- $\beta$ signaling pathways to curtail EMT to MET transition, we did immunoblotting of cell lysates after exposure to various doses of TA extract. Our results suggest that the higher doses of TA extract not only downregulate the phosphorylation status of PI3K-Akt or reduction in TGF- $\beta$-SMAD2/3 expression but also significantly abolish the expression of proteins which play a crucial role in tumor cell invasion, migration, and metastasis. Examples here include MMP-2/9 and MET-associated proteins snail and vimentin. Additionally, exposure of prostate malignant cells to higher doses of TA extract upregulates the protein expression of TIMP1 and E-cadherin, which regulated migration and invasion of cells in a quite different way to that of MET proteins. Together, our results infer that the TA extract promotes antimetastatic activity which includes antimotility, antimigration, and anti-invasion property against prostate malignant cells as displayed in schematic diagram in Figure 8. It does this by attenuating the hyperactivation of aberrant PI3K-Akt signaling and its downstream targets which plays a critical role in tumor metastasis.

\section{CONCLUSION}

Our findings, for the first time, revealed that TA extracts exhibit cytotoxic, anticlonogenic, and antimetastatic properties against prostate cancer cells. Mechanistically, TA extract downregulates the expression of PI3K-Akt and TGF- $\beta$-SMAD2/3 and its downstream target proteins MMP-2, MMP-9, and METassociated proteins snail and vimentin, which play an important role in invasion and migration during the metastasis process. Additionally, we observe the upregulation of tight junction protein expression E-cadherin and TIMP1 in prostate cancer cells when exposed to higher doses of TA extract. We conclude that TA extract has potential anticancer properties that can fight prostate cancer cells. This should be evaluated in preclinical models in future studies to document its therapeutic potential against prostate cancer and other malignancies.

\section{ACKNOWLEDGMENT}

The authors would like to thank the Deanship of Scientific Research, Qassim University, for funding the publication of this project.

\section{AUTHORS' CONTRIBUTIONS}

Conceptualization: Bilal Rah, Abdulmajeed G Almutary, and Abdullah Alnuqaydan. Data curation: Bilal Rah, Abdullah Alnuqaydan, Abdulmajeed G Almutary, and Abdullah Alowaifeer. Formal analysis: Bilal Rah, Abdullah Alnuqaydan, Abdullah M Alajlan, Abdullah Al Tamim, Abdullah Alowaifeer, and Mohd Younis Rather. Funding acquisition: Bilal Rah, Abdulmajeed G Almutary, and Abdullah Alnuqaydan. Investigation: Bilal Rah and Abdullah Alnuqaydan. Methodology: Bilal Rah, Abdulmajeed G Almutary, Abdullah Alnuqaydan, Abdullah M Alajlan, Abdullah Al Tamim, Abdullah Alowaifeer, and Mohd Younis Rather. Project administration: Bilal Rah and Abdullah Alnuqaydan. Resources: Bilal Rah, Abdullah Alnuqaydan, Abdullah M Alajlan, Abdullah Al Tamim, Abdullah Alowaifeer, and Mohd Younis Rather. Software: Bilal Rah, Abdulmajeed G Almutary, Abdullah Alnuqaydan, Abdullah M Alajlan, Abdullah Al Tamim, Abdullah Alowaifeer, and Mohd Younis Rather. Supervision: Bilal Rah and Abdullah Alnuqaydan. Validation: Bilal Rah, Abdullah Alnuqaydan, Abdullah M Alajlan, Abdullah Al Tamim, and Mohd Younis Rather. Visualization: Bilal Rah, Abdullah Alnuqaydan, and Abdullah M Alajlan. Writing original draft: Bilal Rah and Abdullah Alnuqaydan. Writing review and editing: Bilal Rah, Abdulmajeed G Almutary, and Abdullah Alnuqaydan. All the authors have read and agreed to the published version of the manuscript.

\section{CONFLICT OF INTERESTS}

The authors declare there is no conflict of interest.

\section{ETHICAL APPROVAL}

The current study does not involve experiments on animals or human subjects

\section{DATA AVAILABILITY}

The study data is available with authors.

\section{PUBLISHER'S NOTE}

The current journal remains neutral with regard to jurisdictional claims in published institutional affiliation.

\section{REFERENCES}

Al-Abdin OZ, Al-Beeshi IZ. Prostate cancer in the Arab population: an overview. Saudi Med J, 2018; 39(5):453.

Alnuqaydan AM, Rah B. Tamarix articulata (T. articulata)an important halophytic medicinal plant with potential pharmacological properties. Curr Pharma Biotechnol, 2019; 20(4):285-92.

Alnuqaydan AM, Rah B. Comparative assessment of biological activities of different parts of halophytic plant Tamarix articulata (T. articulata) growing in Saudi Arabia. Saudi J Biol Sci, 2020; 27(10):2586-92. Altomare DA, Testa JR. Perturbations of the AKT signaling pathway in human cancer. Oncogene, 2005; 24(50):7455-64.

Arafa MA, Rabah DM. With increasing trends of prostate cancer in the Saudi Arabia and Arab World: should we start screening programs? World J Clin Oncol, 2017; 8(6):447.

Baudino TA. Targeted cancer therapy: the next generation of cancer treatment. Curr Drug Discov Technol, 2015; 12(1):3-20.

Bencherif K, Boutekrabt A, Fontaine, J, Laruelle, F, Dalpè Y, Sahraoui ALH. Impact of soil salinity on arbuscular mycorrhizal fungi biodiversity and microflora biomass associated with Tamarix articulata Vahll rhizosphere in arid and semi-arid Algerian areas. Sci Total Environ, 2015; 533:488-94. 
Björklund M, Koivunen E. Gelatinase-mediated migration and invasion of cancer cells. Biochim Biophys Acta, 2005; 1755(1):37-69.

Buranrat B, Noiwetch S, Suksar T, Ta-Ut A. Inhibition of cell proliferation and migration by Oroxylum indicum extracts on breast cancer cells via Rac1 modulation. J Pharma Anal, 2020; 10(2):187-93.

Cassady JM, Baird WM, Chang CJ. Natural products as a source of potential cancer chemotherapeutic and chemopreventive agents. J Nat Prod, 1990; 53(1):23-41.

Dinicola S, Pasqualato A, Cucina A, Coluccia P, Ferranti F, Canipari R, Catizone A, Proietti S, D'Anselmi F, Ricci G. Grape seed extract suppresses MDA-MB231 breast cancer cell migration and invasion. Eur J Nutr, 2014; 53(2):421-31.

Efferth T. From ancient herb to modern drug: Artemisia annua and artemisinin for cancer therapy. Semin Cancer Biol, 2017; 46:65-83.

Fares J, Fares MY, Khachfe HH, Salhab HA, Fares Y. Molecular principles of metastasis: a hallmark of cancer revisited. Sig Transd Target Ther, 2020; 5(1):1-17.

Hebi M, Hajji L, Eddouks M. Effect of flavonoid-rich extract of Tamarix articulata Vahl. on glucose and lipid metabolism in normal and diabetic rats. Cardiovasc Hematol Agents Med Chem, 2018; 16(2):94-105.

Hebi M, Farid O, Ajebli M, Eddouks M. Potent antihyperglycemic and hypoglycemic effect of Tamarix articulata Vahl. in normal and streptozotocin-induced diabetic rats. Biomed Pharmacother, 2017; 87:230-9.

Hilal L, Shahait M, Mukherji D, Charafeddine M, Farhat Z, Temraz S, Khauli R, Shamseddine A. Prostate cancer in the Arab world: a view from the inside. Clin Genitourin Cancer, 2015; 13(6):505-11.

Hwang HJ, Park HJ, Chung HJ, Min HY, Park EJ, Hong JY, Lee, SK. Inhibitory effects of caffeic acid phenethyl ester on cancer cell metastasis mediated by the down-regulation of matrix metalloproteinase expression in human HT1080 fibrosarcoma cells. J Nutr Biochem, 2006; 17(5):356-62.

Ito K. Prostate cancer in Asian men. Nat Rev Urol. 2014; 11(4):197.

Jothimani M, Loganathan L, Palanisamy P, Muthusamy K. Regulatory pathways of colorectal cancer and their synergistic cross-talk mechanism. Ann Colorect Res, 2020; 8(3):105-19.

Kapinova A, Stefanicka P, Kubatka P, Zubor P, Uramova S, Kello M, Mojzis J, Blahutova D, Qaradakhi T, Zulli A. Are plant-based functional foods better choice against cancer than single phytochemicals? A critical review of current breast cancer research. Biomed Pharmacother, 2017; 96:1465-77.

Katsuno Y, Lamouille S, Derynck R. TGF- $\beta$ signaling and epithelial-mesenchymal transition in cancer progression. Curr Opin Oncol, 2013; 25(1):76-84

Kaur M, Velmurugan B, Rajamanickam S, Agarwal R, Agarwal C. Gallic acid, an active constituent of grape seed extract, exhibits antiproliferative, pro-apoptotic and anti-tumorigenic effects against prostate carcinoma xenograft growth in nude mice. Pharm Res, 2009; 26(9):2133-40.

Kaur R, Kapoor K, Kaur H. Plants as a source of anticancer agents. J Nat Prod Plant Resour, 2011; 1(1):119-24.

Kou B, Liu W, Zhao W, Duan P, Yang Y, Yi Q, Guo F, Li J, Zhou J, Kou Q. Thymoquinone inhibits epithelial-mesenchymal transition in prostate cancer cells by negatively regulating the TGF- $\beta / \mathrm{Smad} 2 / 3$ signaling pathway. Oncol Rep, 2017; 38(6):3592-8.

Kumar S, Weaver VM. Mechanics, malignancy, and metastasis: the force journey of a tumor cell. Cancer Metast Rev, 2009; 28(1):113-27.

Margadant C, Sonnenberg A. Integrin-TGF- $\beta$ crosstalk in fibrosis, cancer and wound healing. EMBO Rep, 2010; 11(2):97-105.

Mehlen P, Puisieux A. Metastasis: a question of life or death. Nat Rev Cancer, 2006; 6(6):449-58.

Parr C, Ali AY. Boswellia frereana suppresses HGF-mediated breast cancer cell invasion and migration through inhibition of c-Met signalling. J Translat Med, 2018; 16(1):1-12.

Patridge E, Gareiss P, Kinch MS, Hoyer, D. An analysis of FDAapproved drugs: natural products and their derivatives. Drug Discov Today, 2016; 21(2):204-7.

Phan MAT, Paterson J, Bucknall M, Arcot J. Interactions between phytochemicals from fruits and vegetables: effects on bioactivities and bioavailability. Crit Rev Food Sci Nutr, 2018; 58(8):1310-29.
Rah B, Amin H, Yousuf K, Khan S, Jamwal G, Mukherjee D, Goswami A. A novel MMP-2 inhibitor 3-azidowithaferin A (3-azidoWA) abrogates cancer cell invasion and angiogenesis by modulating extracellular Par-4. PloS One, 2012; 7(9):e44039.

ur Rasool R, Rah B, Amin H, Nayak D, Chakraborty S, Rawoof A, Mintoo MJ, Yousuf K, Mukherjee D, Kumar LD. Corrigendum: dual modulation of Ras-Mnk and PI3K-AKT-mTOR pathways: a Novel c-FLIP inhibitory mechanism of 3-AWA mediated translational attenuation through dephosphorylation of eIF4E. Sci Rep, 2016; 6(1):1-6.

Rasool RU, Nayak D, Chakraborty S, Faheem MM, Rah B, Mahajan P, Gopinath V, Katoch A, Iqra Z, Yousuf SK. AKT is indispensable for coordinating Par-4/JNK cross talk in p21 downmodulation during ER stress. Oncogenesis, 2017; 6(5):e341.

Rather MA, Bhat BA, Qurishi MA. Multicomponent phytotherapeutic approach gaining momentum: is the "one drug to fit all" model breaking down? Phytomedicine, 2013; 21(1):1-14.

Roodman GD. Mechanisms of bone metastasis. N Engl J Med, 2004; 350(16):1655-64.

Said S, Noureddine G, Eddine LS, Abdelmadjid G, Djamel B, Tliba A. Phenolic content, HPLC analysis and antioxidant activity extract from Tamarix gallica and Tamarix articulata growing in Southeast of Algeria. Res J Pharm Technol, 2018; 11(9):3826-32.

Saji M, Ringel MD. The PI3K-Akt-mTOR pathway in initiation and progression of thyroid tumors. Mol Cell Endocrinol, 2010; 321(1):20

Sarker D, Reid AH, Yap TA, De Bono JS. Targeting the PI3K AKT pathway for the treatment of prostate cancer. Clin Cancer Res, 2009; 15(15):4799-805

Shaalan YM, Handoussa H, Youness RA, Assal RA, ElKhatib AH, Linscheid MW, El Tayebi HM, Abdelaziz AI. Destabilizing the interplay between miR-1275 and IGF2BPs by Tamarix articulata and quercetin in hepatocellular carcinoma. Nat Prod Res, 2018; 32(18):2217-20.

Shukla S, MacLennan GT, Hartman DJ, Fu P, Resnick MI, Gupta S. Activation of PI3K-Akt signaling pathway promotes prostate cancer cell invasion. Int J Cancer, 2007; 121(7):1424-32.

Singh I, Amin H, Rah B, Goswami A. Targeting EGFR and IGF 1R: a promising combination therapy for metastatic cancer. Front Biosci (Schol Ed), 2013; 5:231-46.

Sinha S, Mishra P, Amin H, Rah B, Nayak D, Goswami A, Kumar N, Vishwakarma R, Ghosal S. A new cytotoxic quinolone alkaloid and a pentacyclic steroidal glycoside from the stem bark of Crataeva nurvala: study of anti-proliferative and apoptosis inducing property. Eur J Med Chem, 2013; 60:490-6.

Sreelatha S, Jeyachitra A, Padma PR. Antiproliferation and induction of apoptosis by Moringa oleifera leaf extract on human cancer cells. Food Chem Toxicol, 2011; 49(6):1270-5.

Stavridi F, Karapanagiotou EM, Syrigos KN. Targeted therapeutic approaches for hormone-refractory prostate cancer. Cancer Treat Rev, 2010; 36(2):122-30.

Strasser A, Vaux DL. Cell death in the origin and treatment of cancer. Mol Cell, 2020; 78(6):1045-54

Suardi N, Gallina A, Lista G, Gandaglia G, Abdollah F, Capitanio U, Dell'Oglio P, Nini A, Salonia A, Montorsi F. Impact of adjuvant radiation therapy on urinary continence recovery after radical prostatectomy. Eur Urol, 2014; 65(3):546-51.

Valastyan S, Weinberg RA. Tumor metastasis: molecular insights and evolving paradigms. Cell, 2011; 147(2):275-92.

Vara JÁF, Casado E, de Castro J, Cejas P, Belda-Iniesta C, González-Barón M. PI3K/Akt signalling pathway and cancer. Cancer Treat Rev, 2004; 30(2):193-204.

Verma N, Shukla S. Impact of various factors responsible for fluctuation in plant secondary metabolites. J Appl Res Med Aroma Plants, 2015; 2(4):105-13.

Zhang J, Cunningham JJ, Brown JS, Gatenby RA. Integrating evolutionary dynamics into treatment of metastatic castrate-resistant prostate cancer. Nat Commun, 2017; 8(1):1-9. 
Zhang L, Cheng X, Gao Y, Zhang C, Bao J, Guan H, Yu H, Lu $\mathrm{R}, \mathrm{Xu} \mathrm{Q}$, Sun Y. Curcumin inhibits metastasis in human papillary thyroid carcinoma BCPAP cells via down-regulation of the TGF- $\beta / \mathrm{Smad} 2 / 3$ signaling pathway. Exp Cell Res, 2016; 341(2):157-65.

Zilla MK, Nayak D, Amin H, Nalli Y, Rah B, Chakraborty S, Kitchlu S, Goswami A, Ali A. 4'-Demethyl-deoxypodophyllotoxin glucoside isolated from Podophyllum hexandrum exhibits potential anticancer activities by altering Chk-2 signaling pathway in MCF-7 breast cancer cells. Chem Biol Interact, 2014; 224:100-7.
How to cite this article:

Alnuqaydan AM, Almutary AG, Alshehri OY, Henidi HA, Alajlan AM, Tamim AA, Alowaifeer A, Rather MY, Rah B. Evaluation of the cytotoxic activity of Tamarix articulata and its anticancer potential in prostate cancer cells. J Appl Pharm Sci, 2022; 12(02):089-108. 


\section{SUPPLEMENTARY TABLE}

Supplementary Table 1: Phytochemicals detected from methanolic extract of TA by LC-MS

\begin{tabular}{|c|c|c|c|}
\hline S. No & $\mathbf{M} / \mathbf{Z}$ & RT & Compound \\
\hline 1 & 103.08 & 6.447481 & 3-Methylbutanoic acid;2-Methylbutyrate \\
\hline 2 & 104.04 & 0.781022 & Pyruvate oxime \\
\hline 3 & 105.12 & 16.5714 & Choline \\
\hline 4 & 107.04 & 22.75023 & Aromatic aldehyde; D-Glycerate \\
\hline 5 & 108.96 & 24.27732 & Bromoethane \\
\hline 6 & 119.04 & 11.48668 & Succinic acid \\
\hline 7 & 126.120003 & 1.72972046 & Gamma-Coniceine \\
\hline 8 & 128.04 & 24.26456 & 5-Amino-4-imidazole carboxylate;1-Methyl-4-nitroimidazole \\
\hline 9 & 130.080002 & 0.79923889 & L-Pipecolate \\
\hline 10 & 131.04 & 6.248767 & Itaconate;(E)-Glutaconate \\
\hline 11 & 133.08 & 20.91498 & (R)-2-Hydroxyisocaproate;6-Hydroxyhexanoic acid \\
\hline 12 & 134.04 & 6.839831 & L-Aspartate \\
\hline 13 & 135.12 & 24.28927 & p-Cymene \\
\hline 14 & 136.08 & 8.631082 & 2-Phenylacetamide \\
\hline 15 & 137.04 & 15.86743 & Hypoxanthine; Threonate \\
\hline 16 & 139.08 & 6.450736 & 4-Hydroxyphenylethanol; Styrene-cis-2,3-dihydrodiol \\
\hline 17 & 140.039993 & 7.61881435 & 4-Nitrophenol;2-Nitrophenol;3-Nitrophenol;3-Hydroxypicolinic acid \\
\hline 18 & 142.08 & 8.676849 & Hypoglycin; Arecaidine \\
\hline 19 & 145.08 & 13.84979 & trans-4-Hydroxycyclohexanecarboxylate \\
\hline 20 & 146.039993 & 0.78391111 & alpha-Ketoglutarate \\
\hline 21 & 146.16 & 0.787356 & Spermidine \\
\hline 22 & 147 & 5.374421 & Flupropanate \\
\hline 23 & 147.12 & 13.21838 & L-Lysine \\
\hline 24 & 149.04 & 22.59839 & D-Arabinono-1,4-lactone \\
\hline 25 & 151.08 & 4.124735 & Tolylacetate \\
\hline 26 & 160.080002 & 0.81778333 & Indole-3-acetaldehyde \\
\hline 27 & 161.039993 & 17.2915444 & 2-Oxoadipate \\
\hline 28 & 162.119995 & 6.89406976 & L-Carnitine \\
\hline 29 & 163.08 & 24.28231 & Methyl cinnamate; Safrole \\
\hline 30 & 165.12 & 24.24879 & Jasmone \\
\hline 31 & 189.12 & 11.11041 & Glycyl-leucine \\
\hline 32 & 167.16 & 5.766924 & Robinobiose \\
\hline 33 & 175.08 & 22.49876 & N-Formimino-L-glutamate \\
\hline 34 & 177 & 9.841988 & 3-Chloro-cis,cis-muconate \\
\hline 35 & 178.080002 & 9.75604286 & 4-Hydroxy-4-methylglutamate \\
\hline 36 & 177.12 & 10.12313 & L-Cladinose; Metaldehyde \\
\hline 37 & 181.08 & 8.720061 & D-Glucose \\
\hline 38 & 189.119995 & 11.1007144 & Glycyl-leucine \\
\hline 39 & 193.080002 & 5.79493623 & Carpacin;Myristicin \\
\hline 40 & 197.160004 & 8.60402733 & Linalyl acetate;alpha-Terpinyl acetate \\
\hline 41 & 199.08 & 7.810947 & L-Mimosine \\
\hline 42 & 205.199997 & 9.61738333 & beta-Caryophyllene \\
\hline 43 & 207 & 26.1537176 & Chloroneb \\
\hline
\end{tabular}




\section{SUPPLEMENTARY FIGURE}

\section{Solenopsin A}

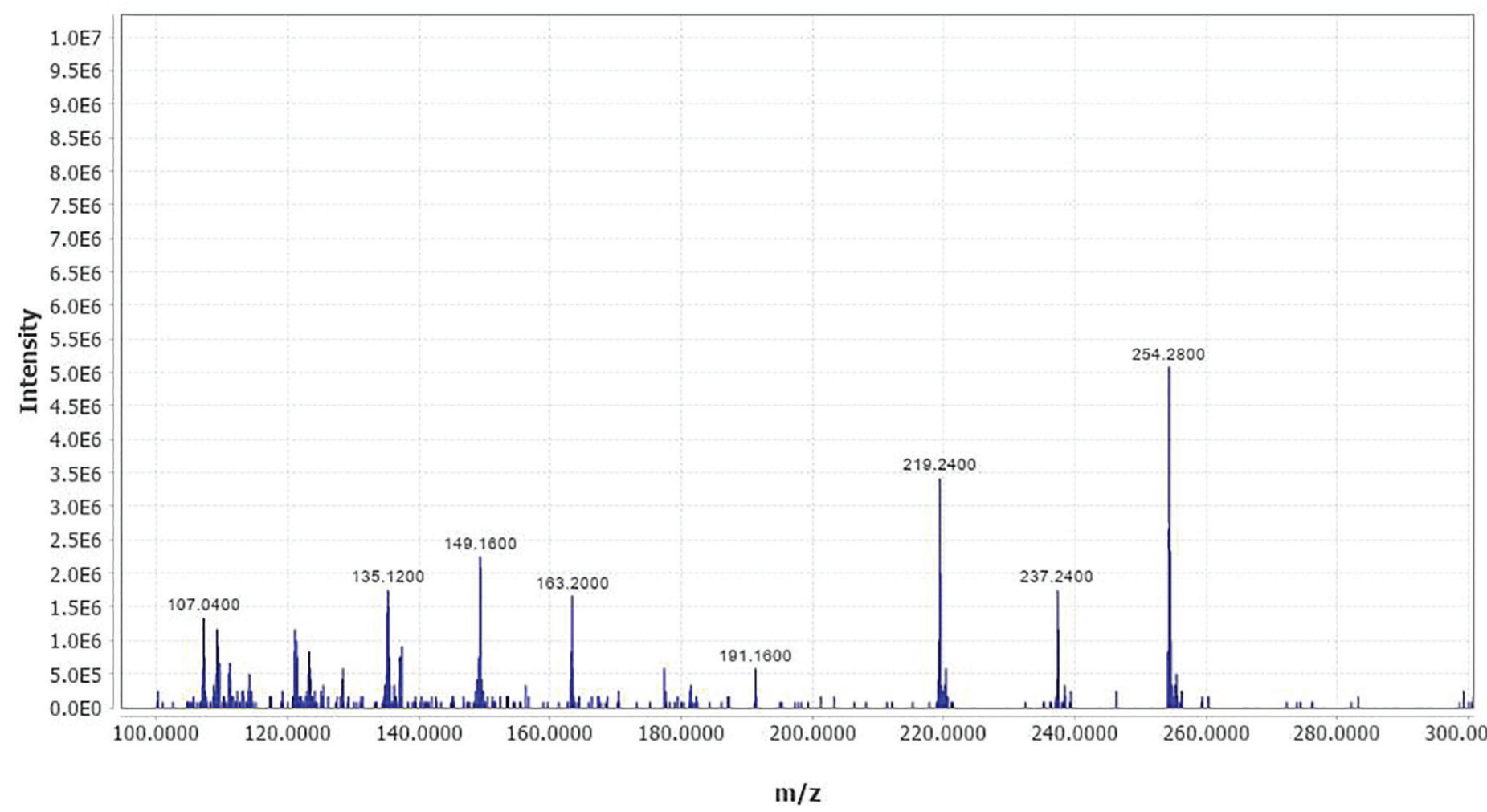

2. Ailanthone

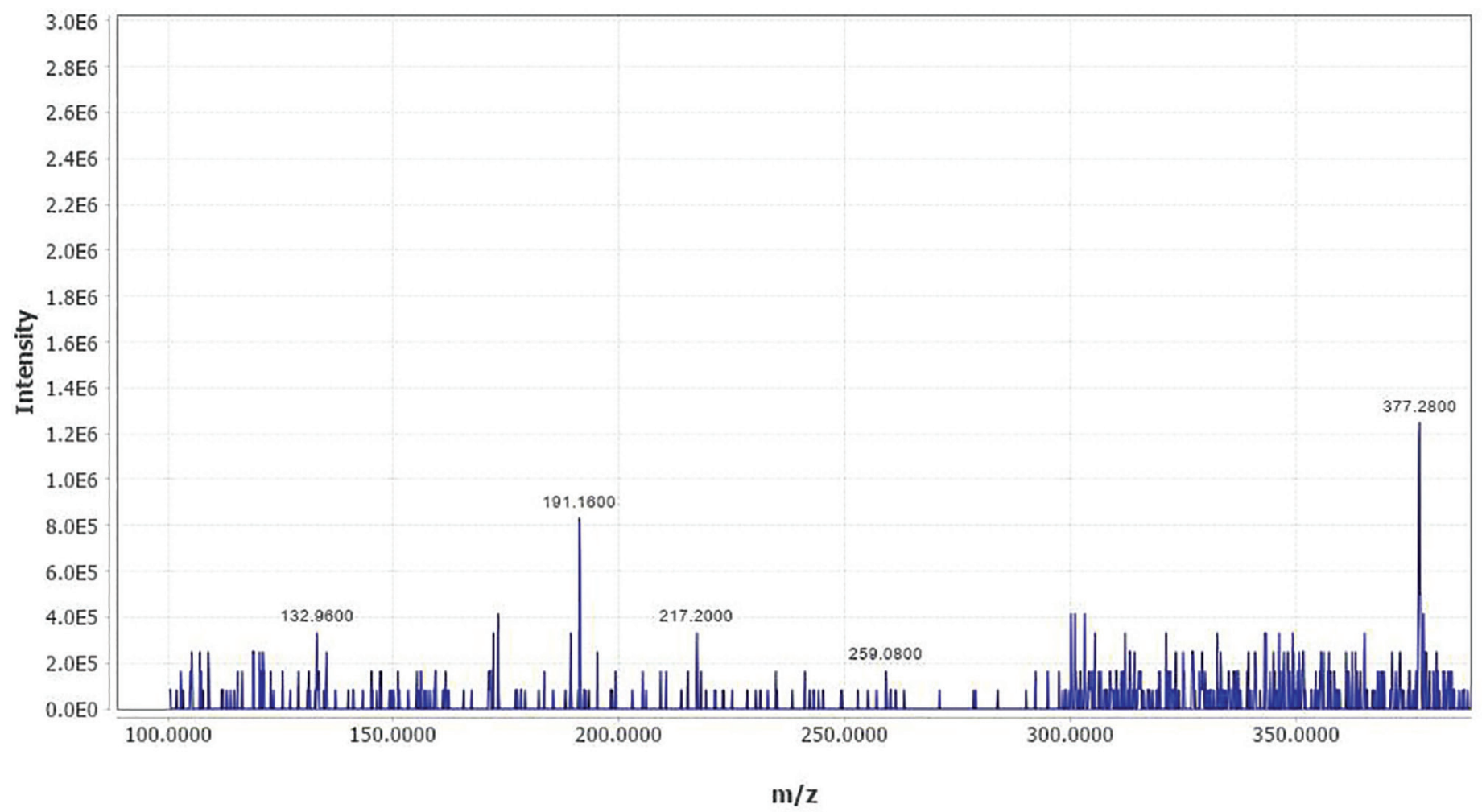



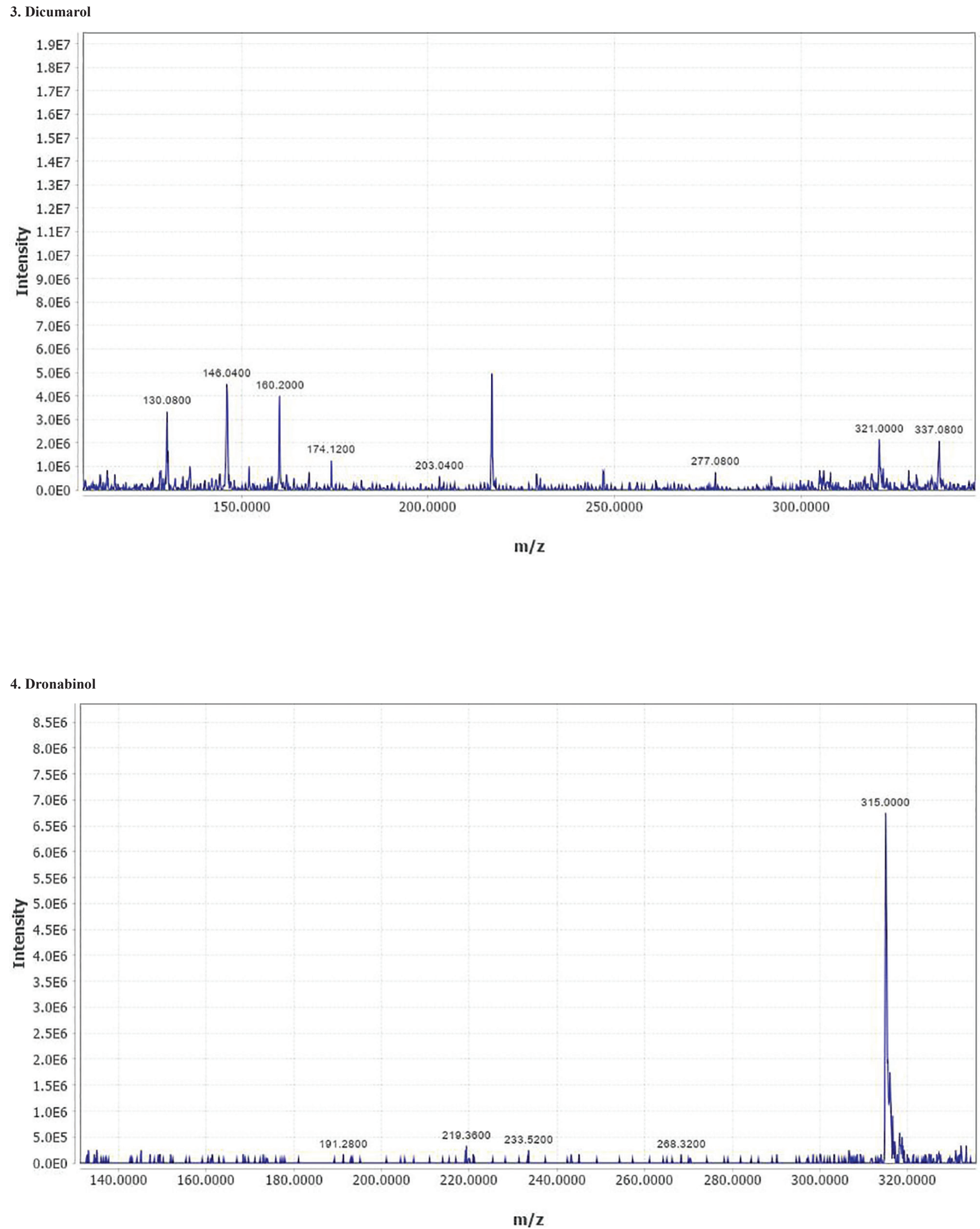


\section{Oxymatrine}

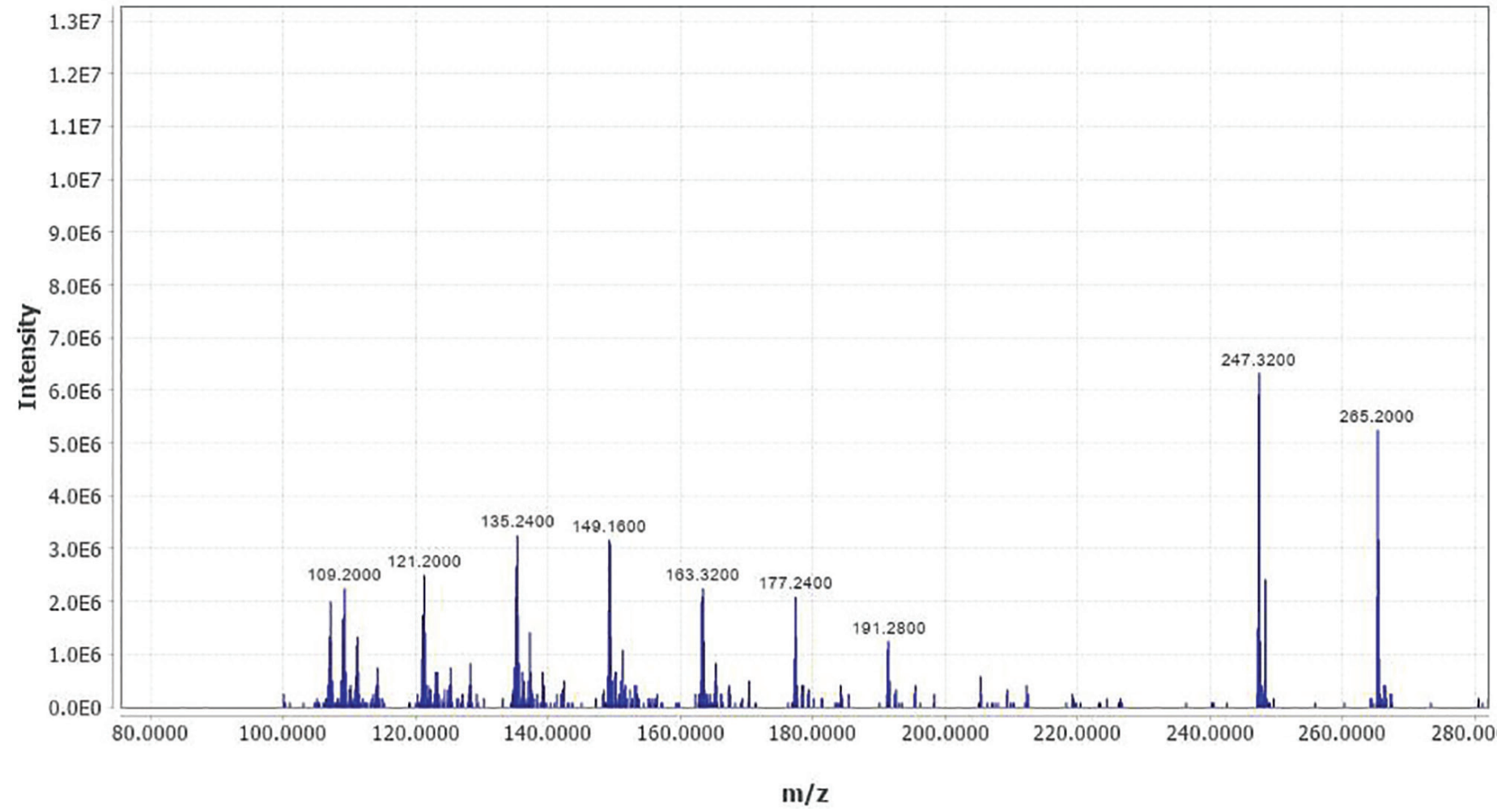

6. Quercetin

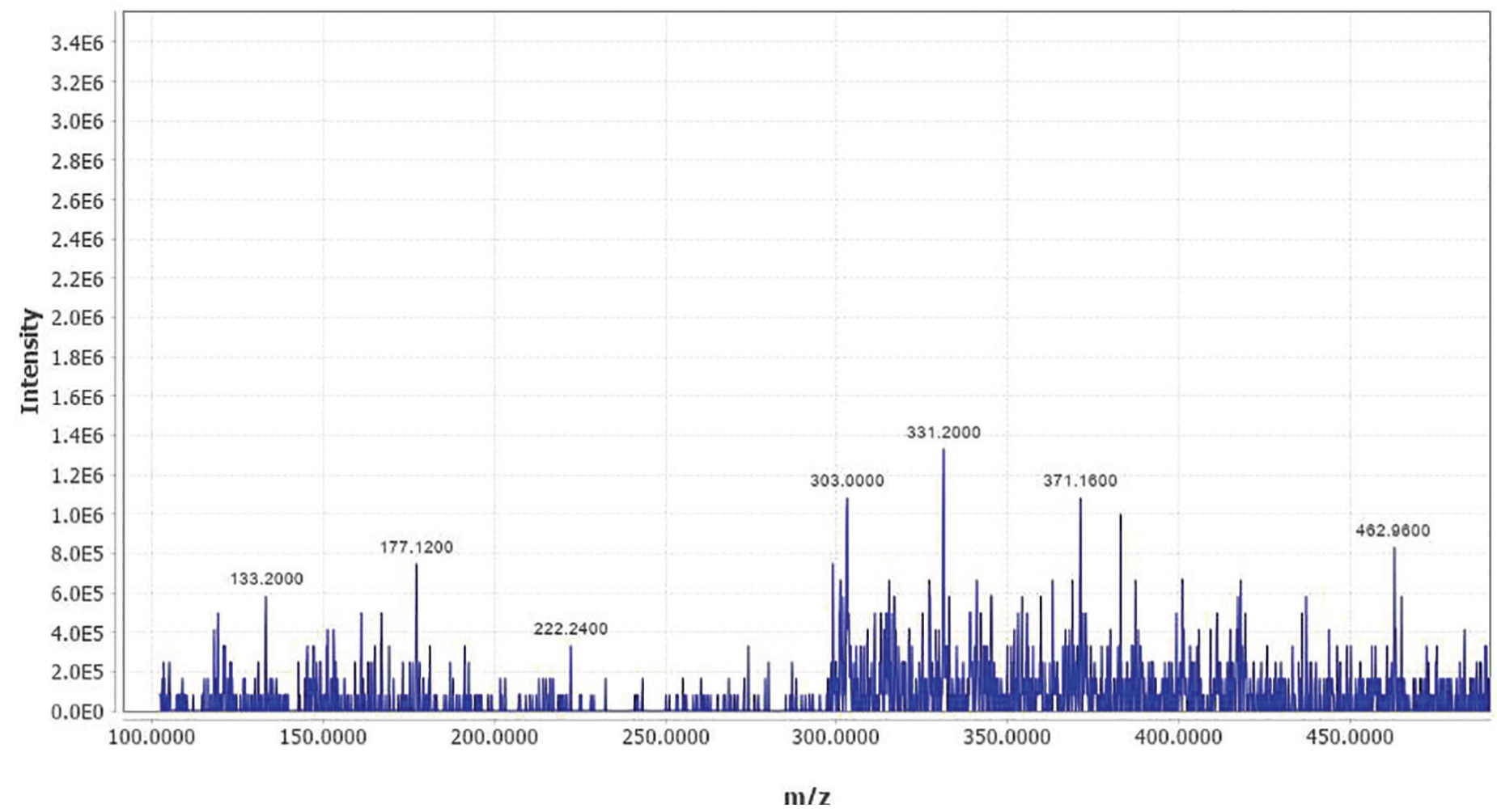




\section{Resveratrol}

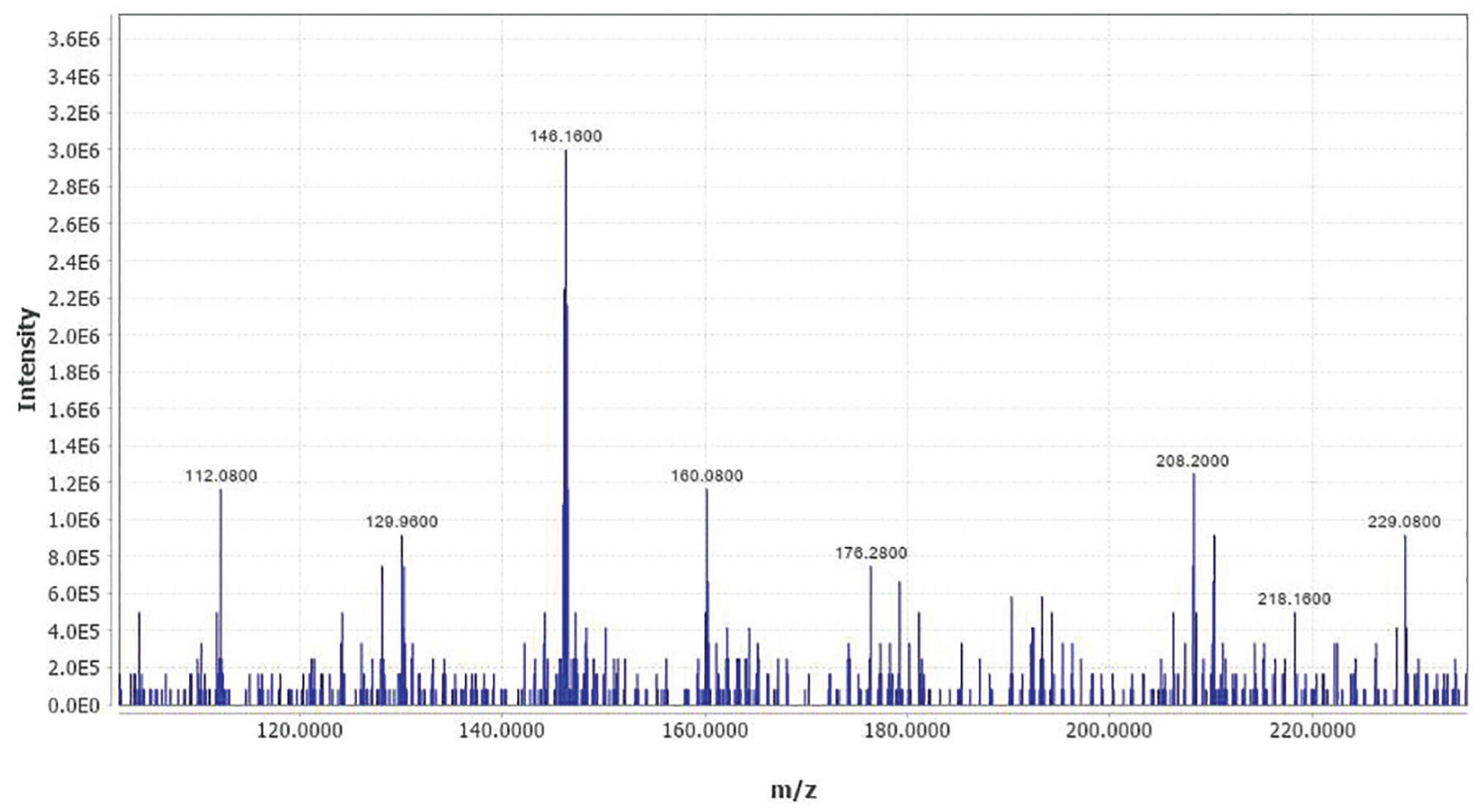

8. Rottlerin

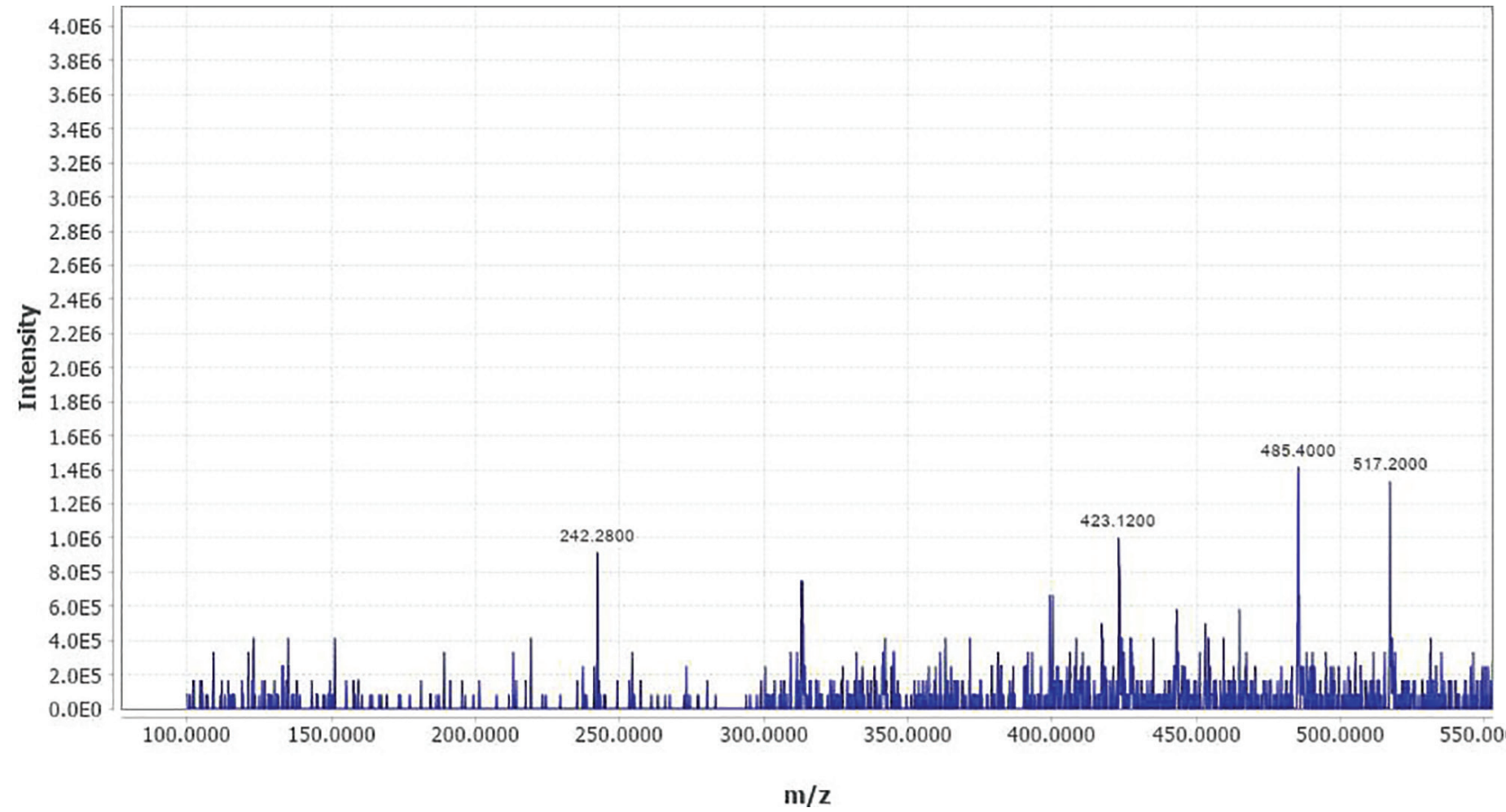

